\title{
MANUFACTURING OF LIGHT METAL MATRIX COMPOSITES BY COMBINED THERMAL SPRAY AND SEMISOLID FORMING PROCESSES - SUMMARY OF THE CURRENT STATE OF TECHNOLOGY
}

\author{
M. Wenzelburger ${ }^{a}$, M. Silber ${ }^{b}$, R. Gadow ${ }^{c}$ \\ Universität Stuttgart, Institut für Fertigungstechnologie keramischer Bauteile (IFKB), Institute for \\ Manufacturing Technologies of Ceramic Components and Composites, Allmandring 7b, Stuttgart, \\ D-70569, Germany \\ amartin.wenzelburger@ifkb.uni-stuttgart.de, ${ }^{b}$ martin.silber@ifkb.uni-stuttgart.de, \\ crainer.gadow@ifkb.uni-stuttgart.de
}

\begin{abstract}
Keywords: Lightweight Engineering, Metal Matrix Composite, Aluminum Matrix Composite, Fiber Reinforcement, Carbon Fiber, Continuous Fiber, Short Fiber, Prepreg, Thermal Spraying, TwinWire Electric Arc Spraying, Semisolid Processing, Thixoforming, Thixoforging.
\end{abstract}

\begin{abstract}
The demand for lightweight structures in the automotive and aerospace industry increases permanently, and the importance of lightweight design principles is also increasing in other industrial branches, aiming towards improved energy efficiency and sustainability. Light metals are promising candidates to realize security relevant lightweight components because of their high specific strength; and amongst them, aluminum alloys are the most interesting materials due to their high plasticity and strain to failure, good processability, passivation in oxygen containing atmosphere, and low cost. However, for many applications, their stiffness as well as strength and fatigue behavior at elevated temperature are insufficient. Metal matrix composite (MMC) formation by integration of reinforcements in the form of continuous or discontinuous (short) fibers can yield a high increase in the alloys' specific mechanical properties at room temperature and at elevated temperature. The integration of fibers with conventional manufacturing techniques like squeeze casting, hot pressing or diffusion bonding leads to restrictions in the component's geometry. Moreover, these techniques result in elevated process costs mainly caused by long cycle times and the need of additional protective fiber coatings. In the present paper, an alternative method for the manufacturing of aluminum matrix composites is described, combining thermal spraying and semisolid forming (thixoforging) technologies for the formation of fiber prepregs and subsequent forming with simultaneous densification. Therefore, prepregs with the matrix alloy as a thick surface coating on the reinforcement fibers are manufactured in a fast, automated coating process, while reheating, densification and shaping are performed in a separate process, allowing an optimization of both processes towards cycle times and resulting material properties.
\end{abstract}

Continuous fiber and short fiber reinforced aluminum matrix composites are manufactured using woven or parallel arranged continuous fibers, or short fibers as a fleece or fiber paper material. For the coating process, twin-wire electric arc spraying is applied as a well established, cost efficient thermal spray technology. The coating process is optimized towards microstructure of the matrix alloy prior to semisolid forming, which requires a globular alloy microstructure, and reduced fiber damage during the high-temperature liquid melt deposition. The thermally sprayed fine-grained matrix material enables semisolid forming at liquid contents of 40-60 vol\% of the alloy, with short flow paths, reduced mechanical loads and short cycle times. Thus, limited fiber damage and residual stresses will occur, leading to good mechanical material properties. A production line for industrial-scale coating of fiber fabric coils in a continuous process is introduced in order to provide prepregs of various fiber-reinforcement materials and fiber architectures; moreover, a winding equipment for simultaneous fiber winding and coating is presented that enables local reinforcement for components with adapted, tailored composite material design. 


\section{Introduction}

This paper describes a manufacturing process for fiber reinforced aluminum alloys. Thereby, fiber preforms consisting of short fibers, woven fiber cloth or unidirectional (UD) fiber reinforcement are coated with the matrix alloy by a thermal spraying process. The fiber/matrix alloy prepreg is used for further densification and forming by a semisolid forging process. This new method is a promising alternative to conventional manufacturing processes for fiber reinforced light metals regarding manufacturing cost, flexibility of materials, preservation of the carbon fiber properties in the composite, and degree of formability during semisolid forging.

Why Metal Matrix Composite Materials? Aluminum matrix composites are interesting lightweight materials for special applications that require better creep and fatigue behavior (mainly at elevated temperatures) as well as increased wear resistance than unreinforced light metals or fiber reinforced polymers. Moreover, stiffness and absolute strength can be significantly increased by composite formation with suitable reinforcement phases like particles, short fibers or continuous fibers. Mainly the specific properties taking into account the density of materials are important factors in lightweight engineering; however, they are not in any case superior for unreinforced light metals like aluminum or magnesium alloys as compared to steel, because the absolute mechanical performance of light metals is generally lower. Fig. 1 shows the specific modulus and specific strength of different materials according to Ashby [1].

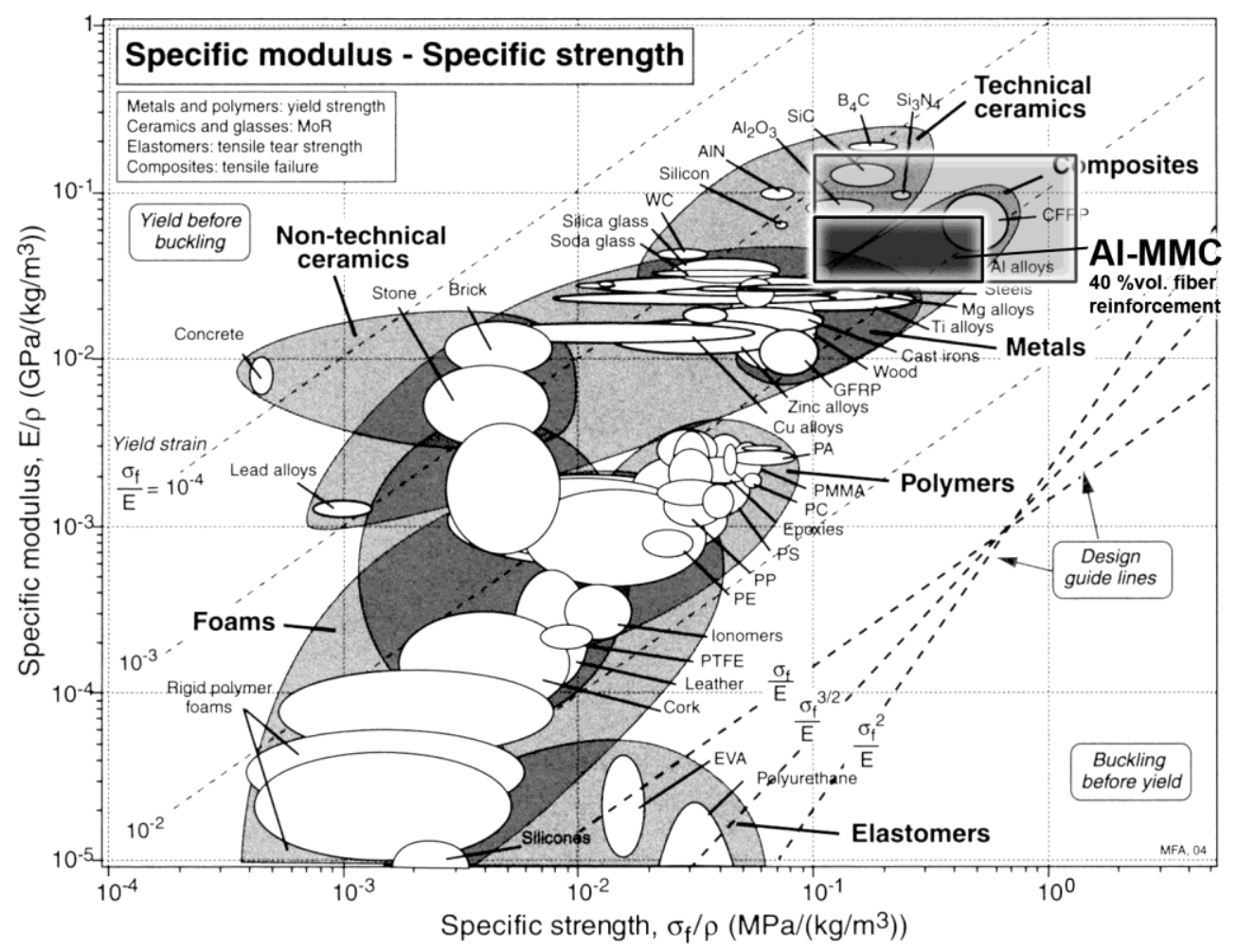

Fig. 1: Specific modulus E/ $\rho$ vs. specific strength $\sigma_{\mathrm{f}} / \rho$ of different classes of materials [1]; with boundaries (max. theoretical and true values) of fiber reinforced $\mathrm{Al} 6 \mathrm{Si}-\mathrm{MMC}$ specific properties

The inclusion of ceramic fiber materials like carbon fibers as reinforcement phase in order to form a metal matrix composite leads to an increase in mechanical properties of light metals (however, strain to failure is generally decreased for MMC materials in comparison to unreinforced alloys), and furthermore, can also lead to a decrease of material density in case of carbon fibers. E. g., for $\mathrm{Al} 6 \mathrm{Si}$ alloy with a density of $2.7 \mathrm{~g} / \mathrm{cm}^{3}$ with C-fiber reinforcement of $40 \mathrm{vol} \%$ and a density of HT carbon fibers of $1.76 \mathrm{~g} / \mathrm{cm}^{3}$, the density of the final $\mathrm{MMC}$ is $\rho_{\mathrm{C}(\mathrm{HT}) \mathrm{F} / \mathrm{Al} 6 \mathrm{Si}}=2.32 \mathrm{~g} / \mathrm{cm}^{3}$. Assuming a 
simultaneous increase in Young's modulus from $70 \mathrm{GPa}$ to $138 \mathrm{GPa}$ according to the Voigt model for axial loading (equal strain assumption in composite theory), see Eqn. 1 [2], and an increase in tensile strength from $130 \mathrm{MPa}$ to $260 \mathrm{MPa}$, the specific material properties weighted by the materials' densities are highly increased for the composite material.

$$
E_{\text {Voigt,axial }}=(1-f) E_{M}+f E_{F}
$$

In this work, the aluminum-silicon alloy $\mathrm{Al} 6 \mathrm{Si}$ was applied due to its good mechanical properties, large temperature regime for semisolid forming, and comparability with A356 and A357.0 alloys, which are common alloys in the automotive industry.

The specific properties' area for MMC with a matrix of $\mathrm{Al} 6 \mathrm{Si}$ aluminum alloy and different fiber reinforcement materials (carbon, silicon carbide, alumina and basalt fibers) for a constant reinforcement fraction of $\mathrm{f}=40 \mathrm{vol} \%$ has been included in Fig. 1 for comparison with structural bulk materials (metal and technical ceramics) and with polymer composites. Thereby, the maximum specific values for Young's modulus and strength (lighter area in Fig. 1) are theoretical limits, considering the highest possible values for fiber properties, unidirectional reinforcement with loading in axial direction, and thus calculation of properties by the rule of mixtures with the Voigt model (Eqn. 1). Realistic properties for fiber reinforced aluminum alloys are lower, mainly concerning the strength while the stiffness calculated by the rule of mixtures yields values that are relatively close to experimental data (however, realistic stiffness values are given lower here due to the fact that very high modulus carbon fibers are very expensive and would not be used in broad industrial application). Boundaries for realistic specific properties are given as the darker area in Fig. 1. Properties of the alloy as well as fiber materials considered in this work are given in Tab. 1, along with standard (high performance) aluminum alloys for comparison reasons.

Table 1: Physical and mechanical properties of $\mathrm{Al} 6 \mathrm{Si}$ aluminum alloy and reinforcement fiber materials applied in this work (plus some convenient alloys as reference materials) [var. sources]

\begin{tabular}{|c|c|c|c|c|c|}
\hline Material & $\begin{array}{l}\text { Density, } \\
\rho\left(\mathrm{g} / \mathrm{cm}^{3}\right)\end{array}$ & $\begin{array}{l}\text { Young's Modulus, } \\
\mathrm{E}(\mathrm{GPa})\end{array}$ & $\begin{array}{l}\text { Tensile Strength, } \\
\mathrm{UTS}, \sigma_{\mathrm{t}, \mathrm{m}}(\mathrm{MPa})\end{array}$ & $\begin{array}{l}\text { Yield Strength, } \\
\text { YS, } \sigma_{\mathrm{y}}(\mathrm{MPa})\end{array}$ & $\begin{array}{l}\text { Strain to Failure, } \\
\varepsilon(\%)\end{array}$ \\
\hline $\begin{array}{l}\text { Al 6Si spray wire (similar } \\
\text { to AA 4043A [Al Si5]) }\end{array}$ & 2.7 & 70 & 130 & 70 & 15 \\
\hline Al Si7Mg0.3 (AA A357.0) & 2.65 & 72.4 & $200-340$ & $120-280$ & $2-9$ \\
\hline $\begin{array}{l}\text { Al Si17Cu4Mg (hyper- } \\
\text { eutectic alloy Alusil }{ }^{\circledR} \text { ) }\end{array}$ & 2.73 & 80 & $165-370$ & $170-360$ & $0.2-1.0$ \\
\hline Al Mg1SiCu (AA 6061) & 2.70 & 70 & $120-300$ & $85-240$ & $3-18$ \\
\hline $\begin{array}{l}\text { Al Cu4Mg1 (AA 2024, } \\
\text { duraluminium or Dural }^{\circledR} \text { ) }\end{array}$ & $2.75-2.87$ & 73 & $420-500$ & $140-400$ & $<22$ \\
\hline Carbon fiber, HT type & 1.76 & $200-300$ & $3,000-7,000$ & - & $1.7-2.4$ \\
\hline Carbon fiber, IM type & 1.80 & $240-300$ & $3,000-6,000$ & - & $1.4-1.9$ \\
\hline Carbon fiber, HM type & 1.93 & $350-820$ & $1,400-4,500$ & - & $0.2-1.1$ \\
\hline Alumina fiber Nextel 610 & $3.75-3.88$ & 373 & $1,900-2,930$ & - & - \\
\hline SiC-based fibers (Nicalon) & $2.4-3.1$ & $190-420$ & $2,800-3,800$ & - & $0.6-1.6$ \\
\hline Tyranno fiber (Si-Ti-C-O) & $2.3-2.4$ & 206 & 2,700 & - & 1.6 \\
\hline Basalt fiber & 2.75 & $90-100$ & $3,000-4,800$ & - & $3.1-3.5$ \\
\hline
\end{tabular}

The integration of fiber reinforcement into a light metal alloy is leading to higher cost of processing and raw materials, and thus limited application possibilities of such high-end lightweight materials. However, composite materials with aluminum alloys as matrix are suitable to modify the materials' properties in a large range, which may enable weight savings in critical components that have a high economic potential or a system relevant importance in terms of technical performance or reliability. Examples for fiber reinforced aluminum today are frame elements in helicopter rotors or aircraft landing gears. Further efforts towards lightweight design in passenger cars could enable the application of fiber reinforced aluminum in the power train or chassis of future automobiles. 
Problems in MMC Manufacturing - Motivation and Approach. The highest potential to increase the specific mechanical properties of light metal MMC is provided by fiber reinforcements. The basic requirement to utilize the fiber properties in the composite material is a homogeneous fiber integration with optimized fiber matrix interfaces. During melt infiltration processes in fiber preforms, wettability of fibers by the melt plays a decisive role for optimized fiber incorporation [3, 4]. For polymer matrix composite (PMC) materials, high fiber contents up to $60 \mathrm{vol} \%$ can be achieved with low fiber damage and good matrix-to-fiber adhesion, whereas liquid aluminum, silicon, magnesium or titanium melts react with carbon fiber surfaces, leading to fiber degradation and damage as well as the formation of reaction products (e. g., aluminum carbide) at the interface [5-7]. Optimization of the interface means to provide sufficient fiber/matrix bonding without damaging the fibers chemically or mechanically, which may be achieved by appropriate protection of the fibers with coatings, or by adapted infiltration processes. Furthermore, PMC manufacturing processes run at lower temperatures than MMC processes, which results in lower residual stresses within the composites, while for MMC, high normal and shear stresses can occur at the interface that reduce the aspired composite properties.

For PMC materials, new and specific manufacturing methods have been developed over the years for optimization of composite density, homogeneous fiber distribution and reduction of fiber disorientation during polymerization of the liquid resins. Many of these technologies are used also for the manufacturing of precursors for ceramic matrix composites (CMC), which are processed by thermal conversion and subsequent in-situ reaction to form the ceramic matrix. Another specific manufacturing process for $\mathrm{CMC}$ is the deposition of matrix material from the gas-phase on preorientated fiber preforms. That means, for PMC as well as CMC material and components, specific manufacturing technologies have been developed to control wetting, distribution and orientation of the reinforcement, and thus optimize the final properties of the composites.

However, for metal matrix composites, manufacturing processes are generally derived from conventional metal processing. Present manufacturing technologies for MMC can be divided into three main groups: casting technologies, powder metallurgical processes and, mainly for particle reinforced material, atomization techniques. The powder metallurgical, solid state techniques (e. g., diffusion bonding) show reduced chemical reaction, and thus damage of the fibers, but the design of the components is strongly limited to simple geometries, and process cycle times are high [8]. More complex geometries can be realized with liquid metal infiltration, e. g. squeeze casting, gas pressure infiltration, or high pressure die casting, which can also be supported by vacuum (Vacural ${ }^{\circledR}$ process) [9]. Thereby, the preform is infiltrated by a 100 vol\% liquid fraction of the metal, leading to significant fiber damage by chemical reaction at the interface and additionally, high mechanical loads to the fibers during infiltration [2]. Only few expensive reinforcement materials (e. g., alumina or $\mathrm{SiC}$ fibers) can withstand these conditions. Therefore, both standard procedures are leading to problems in component manufacturing, material properties or cost of the process.

To enable cost efficient applications and high performance MMC materials, manufacturing processes with short cycle times, low investment cost of the equipment, and the possibility of variable fiber reinforcement design are needed. The approach discussed in this paper is the manufacturing of aluminum MMC by the use of coated fiber layers ("fiber prepregs") that are further processed by thixoforging for densification and shaping of the final MMC component. This process route is suitable to solve the problem of long process cycle times and fiber damage by contact with metal melts. The semisolid state of the metal and the short forming times prevent chemical interaction with the fibers. The required globular microstructure of the metal phase for the thixoforming process is provided by a thermal spraying process used for coating and preimpregnation of the fibers with the matrix metal. Thereby, the coating thickness determines the final fiber volume content in the composite. Moreover, thixoforging of the coated and laminated fibers offers the possibility to manufacture net-shape components with tailor-made fiber distribution and content [10]. 
The orientation of fibers has a significant influence on the final mechanical properties of the composite. Most applications require a well-defined orientation of the reinforcement in one spatial direction. However, if there are mechanical loads in different directions, the fiber-orientation should be customized to 2D or even complex 3D multi-directional continuous reinforcements, e. g. [11]. The introduced technology for MMC manufacturing allows the flexible processing of tailored fiber structures. Therefore, different fiber structures are studied in this paper, which are randomly distributed short fibers, continuous unidirectional (UD) fiber reinforcements, fiber reinforcements with 2D woven fabric structure and tailored local fiber reinforcements that are integrated in the matrix by simultaneous winding and coating.

Outline of the Paper. Due to the different approaches in architecture of the fiber reinforcement, different manufacturing processes in terms of equipment and optimization of the coating process were developed. Therefore, describing the state of technology and common effects during densification of fiber prepregs, and then following a hierarchical system with increasing definition of the reinforcement arrangement, this paper is separated into six main sections:

- State of science and technology, or general remarks on semisolid processing and the thermal spraying technologies,

- Thixoforging of thermal spray (TS) coated fiber prepregs,

- Short fiber reinforced aluminum as a quasi-isotropic material with random fiber orientation,

- Continuous fiber reinforced aluminum with textile, 2D fiber reinforcement,

- Continuous fiber reinforced aluminum with unidirectional (UD) fiber orientation, and

- Tailored local reinforcement with continuous fibers.

Thereby, the process technology for manufacturing of tailored reinforcement with well-defined fiber embedding in critical areas of a light metal component is still under development and will be presented in an extended outlook.

\section{State of Science and Technology}

Semisolid Forming (Thixoforging) of Light Metals. Semisolid forming is forming of metals at temperatures above the solidus and below the liquidus temperature, where solid and liquid phases coexist, see Fig. 2. At liquid fractions of about $20-60 \mathrm{vol} \%$, the metals can show a thixotropic (shear thinning) flow behavior. In order to obtain such a flow behavior during thixoforging, it is necessary to have a globular and not a dendritic structure of the solid phase. The solid globular phase forms a scaffold with the liquid phase in the interspaces, remaining firm if loads are lower than the critical shear stress for thixotropy. In this state, the material can be handled like a solid block. By applying higher shear stresses to the semifinished material, the scaffold breaks up and viscosity as well as yield stress decrease significantly. The globular shape of the grains is necessary for that effect, because it supports easy shearing and sliding of the material, see Fig. 3 (right). In contrast, for a dendritic metal structure (Fig. 3, left), the dendrites inhibit easy relative movement of the solid grains, and thus formability of the material. This structure is typically obtained by casting processes.

Semisolid forming allows the production of components with complex geometries and high strength by achieving high deformation rates under comparatively low forces [12]. Moreover, fast cooling of the component after solidification will preserve the fine, globular microstructure of the semifinished material in the final component $[13,14]$.

Typical processing temperatures of aluminum alloys with silicon as the main alloying element (4xxx series) are $500-540{ }^{\circ} \mathrm{C}$ for forging, approx. $660-700{ }^{\circ} \mathrm{C}$ for casting, and $577-650{ }^{\circ} \mathrm{C}$ for thixoforging, depending on the alloy composition and desired liquid content. E. g., thixoforging of AA 6082 and AA A356 demands processing temperatures of $638-642{ }^{\circ} \mathrm{C}$ and $577-586{ }^{\circ} \mathrm{C}$, respectively $\left(577^{\circ} \mathrm{C}\right.$ : melting temperature of the eutectic). Depending on the content of the liquid 
fraction, semisolid forming, or rather thixoforming, is divided into thixoforging and thixocasting $[12,15]$.

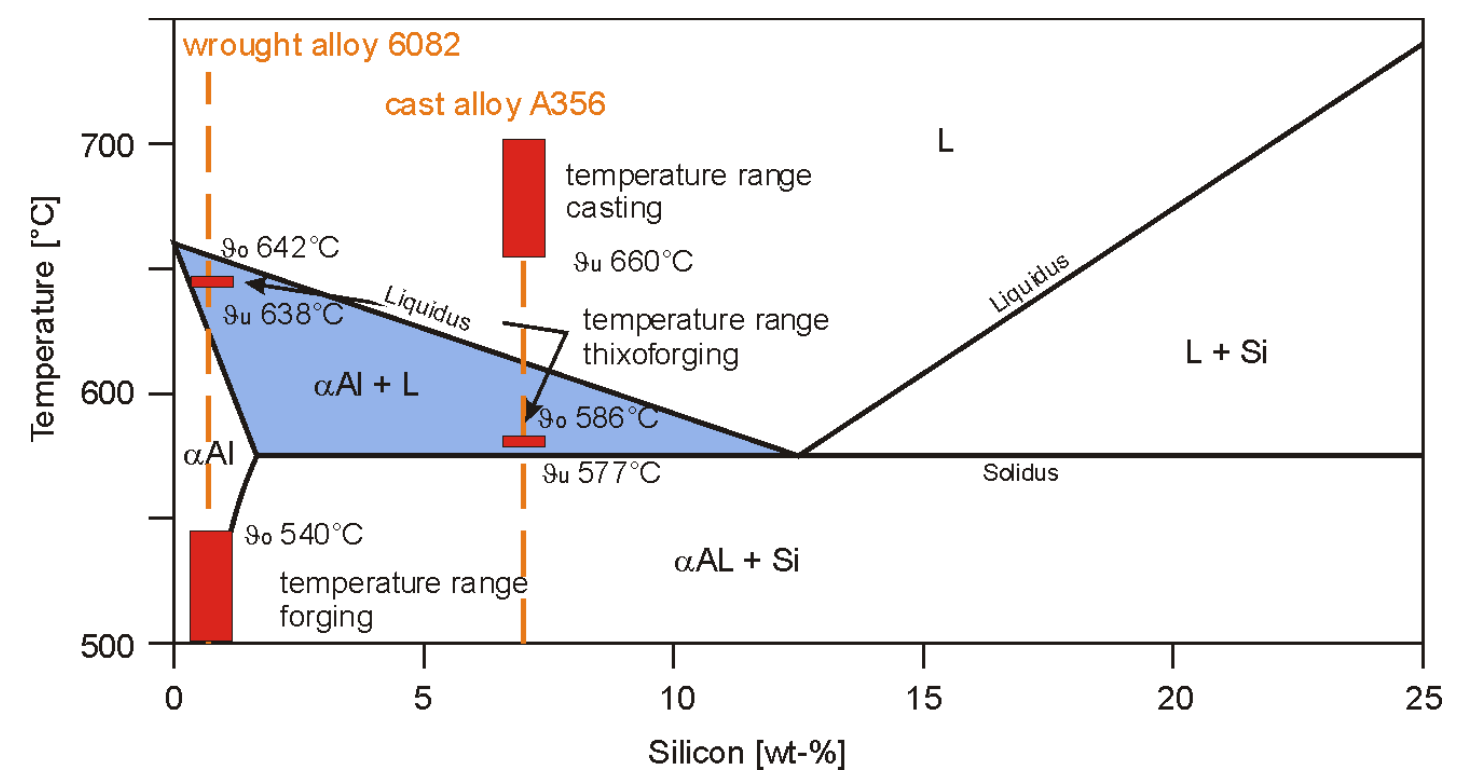

Fig. 2: Processing intervals for casting, forging, and thixoforging of AA 6082 (Al MgSi1) and AA A356 (Al Si7Mg) in the binary aluminum-silicon phase diagram [13]
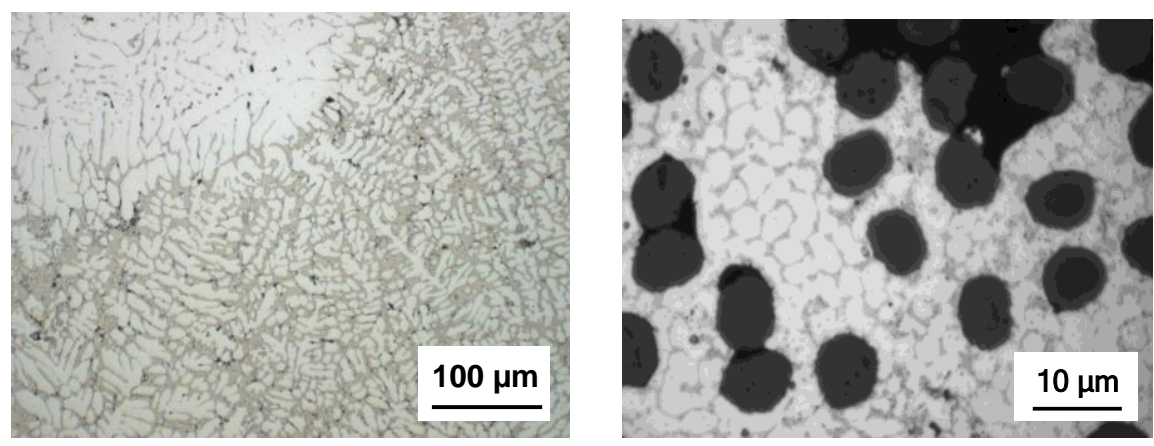

Fig. 3: Dendritic structure of thermally sprayed, reheated and forged AA 2017 (Al Cu4MgSi) after slow cooling (left); globular structure of $\mathrm{C}$-fiber reinforced $\mathrm{Al} 6 \mathrm{Si}$ after thermal spraying and reheating to thixoforging temperature (SEM, right)

All semisolid processing methods require a globular microstructure of the metal during heating and forming. For this reason, in most cases the alloys used for thixoforging are stirred electromagnetically during continuous casting of the billet rods. Another possibility to reach a fine grained globular material is spray forming [16]. In the present work, the thermal spray technology is applied, for which process characteristics involve high kinetic energy of the molten spray material, quenching of the material on the substrate surface, and rapid solidification [17]. These process parameters provide a quasi globular shape of the $\alpha$-aluminum solution. Therefore, thermally sprayed metals show a thixotropic behavior of the viscosity during forming processes (after heating of the material into a temperature range to adjust a liquid metal fraction of 40-60 vol\%).

Thixoforging combines the features of casting, i. e. near-net-shape production of complex parts and low wall thickness, with the advantages of forging, like high strength, high elongation as well as fine-grained microstructures. Thereby, further advantages of the process for the manufacturing of fiber reinforced light metal MMC are:

- low process temperatures in comparison to liquid melt infiltration and 
- reduced cycle times of the combined reheating and thixoforging process due to fast solidification and short flow paths, thus

- limitation of chemical reactions at the fiber surfaces, and

- limitation of residual stresses (which arise from the misfit in thermal expansion between the matrix material and the reinforcement), and furthermore,

- improved mold durability due to reduced liquid fraction and low press forces.

However, in order to make the advantages of semisolid forging applicable to fiber prepregs and the manufacturing of fiber reinforced MMC, the process has to provide fast reheating, fast transport of the hot semifinished material into the die, and fast cooling after thixoforging. If the complete processing chain, reheating unit, material handling and control of the press is included in component design and process optimization, the MMC manufacturing method proposed here can be an interesting method not only regarding component properties, but even in terms of cost.

Thermal Spray Processes. In conventional thixoforming processes, the required material's microstructure is created e. g. by electromagnetic stirring or spray forming of a melt in order to produce a bulk material. During spray forming, a melt is atomized in inert atmosphere by a nitrogen jet and sprayed onto a substrate to form a billet. Thereby, rapid solidification almost completely inhibits segregation processes [16]. The thermal spray methods show a similar mechanism, providing a suitable matrix microstructure for thixoforging. However, in thermal spraying, substrates with a larger surface area (e. g., fiber fabrics or fiber fleece) can be coated directly with a uniform coating thickness.

Thermal spraying leads to a lamellar, splat-like and inhomogeneous microstructure, see Fig. 4 for a schematic view of material deposition and coating formation. However, due to fast quenching and solidification within $10^{-5}$ to $10^{-7}$ seconds [17], the grains within single splats are almost globular, which leads to good processability of thermally sprayed materials by semisolid forming.
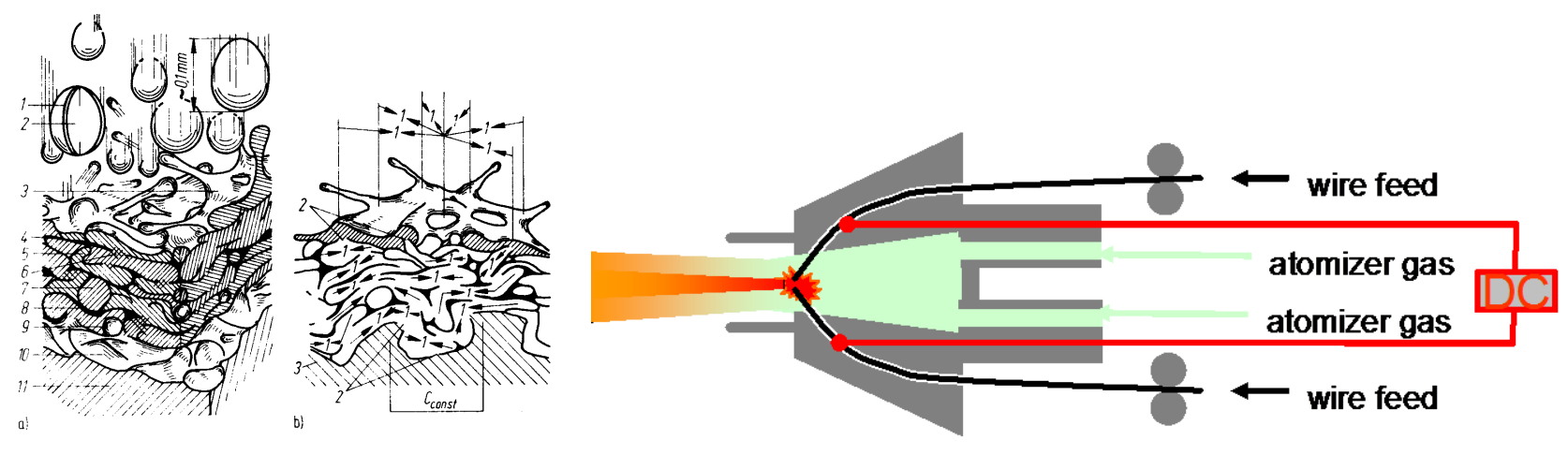

Fig. 4: Lamellar coating formation and structure [18] (left) and principle sketch of the twin-wire electric arc spraying process (right)

Because of the high deposition rate and low heat transfer to the substrate, the industrially well established twin-wire electric arc spraying technique was applied in this work. The thermal spray equipment applied was a DC inverter power source type GTV Sparc 400, GTV Verschleiss-Schutz GmbH, Luckenbach (Germany).

The twin-wire electric arc process applies an electric arc in order to melt the tips of two electrically conductive wires consisting of the coating material. The wires are fed constantly and the melt is atomized and propelled towards the substrate by a jet of compressed air, providing stability of the electric arc at the point of contact of the wires, see Fig. 4. The coating formation is the result of the molten metal particles impacting one upon the other. The arc wire spraying process is cost effective and it is run in atmosphere with only minor oxidation of the matrix material in the region of $<0.01 \mathrm{wt} \%$ oxide content for aluminum-silicon alloys [19]. 
In order to verify the ability of the thermally sprayed coatings to serve as a feedstock with thixotropic flow behavior, investigations of the grain structure as well as forging experiments were carried out. In the first step, thermal spraying was analyzed with respect to its suitability for the formation of a globular microstructure. Therefore, a thermally sprayed coating was analyzed by means of focused ion beam (FIB) microscopy, which discovered a fine grained structure within the sprayed coatings with grain sizes $<1 \mu \mathrm{m}$, see Fig. 5 .

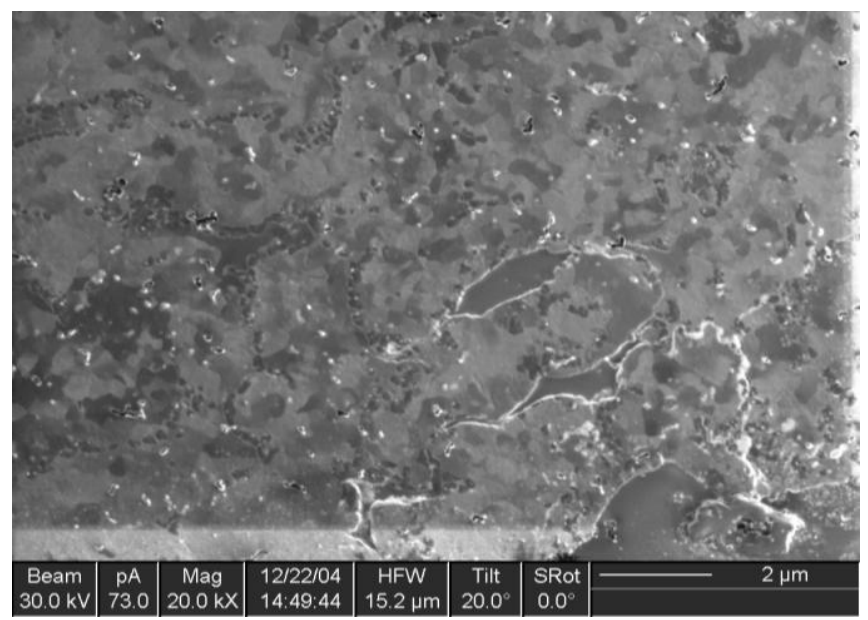

Fig. 5: Focused ion beam (FIB) microscopy of the fine grained structure of thermally sprayed Al 6Si [20]

In a second step, solid $\mathrm{Al} 6 \mathrm{Si}$ billet rods were deposited under atmospheric conditions by twin-wire electric arc spraying. They were heated into the semisolid temperature regime of the alloy and maintained sufficient form stability for handling, but could be cut easily with any tool, which was verified by a knife cutting test, see Fig. 6 (left). The microstructure of the billet rods after heating and forging is shown in Fig. 6 (right). Grain growth occurred during reheating, forming and cooling; however, the average grain sizes are still in the region of $10-20 \mu \mathrm{m}$. This grain growth effect was also due to the long heating time of the massive billets and is highly reduced for the thixoforging of thermal spray (TS) prepregs.
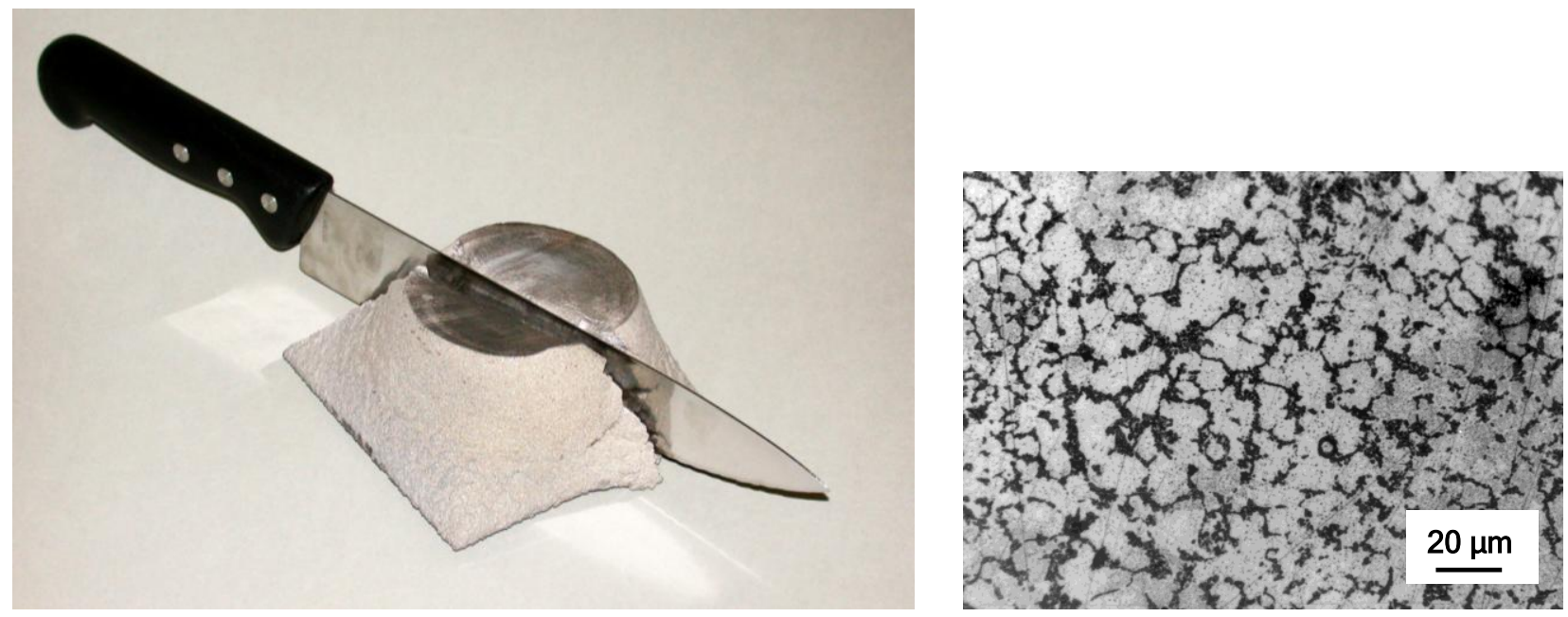

Fig. 6: Al 6Si thermal spray cone (billet), $100 \mathrm{~mm}$ in diameter, heated into the semisolid state and cut easily with a kitchen knife (left); microstructure of an Al 6Si billet rod after heating and forging

Regarding composite formation by thermal spraying of metals on reinforcement fibers (prepreg manufacturing), first experiments have been described by Steffens et al. [21, 22]. However, thermal spraying with plasma or twin-wire electric arc was only performed under vacuum or inert gas, and only tungsten, $\mathrm{SiC}$, or steel fibers (X $12 \mathrm{CrNi} 17$ 7, X $5 \mathrm{CrNi} 18$ 10) were used as reinforcement. As matrix materials, Ni80Cr20, TiAl6V4, X 5 CrNi 18 9, or NiCr 19 Al 6Si were applied. Composite 
densification of layered prepregs was made by hot isostatic pressing (HIP). In [22], a fiber winding and coating technique was described for the manufacturing of flat, UD continuous fiber reinforced prepregs, see Fig. 7. This technique was adapted in the present work for prepreg manufacturing.

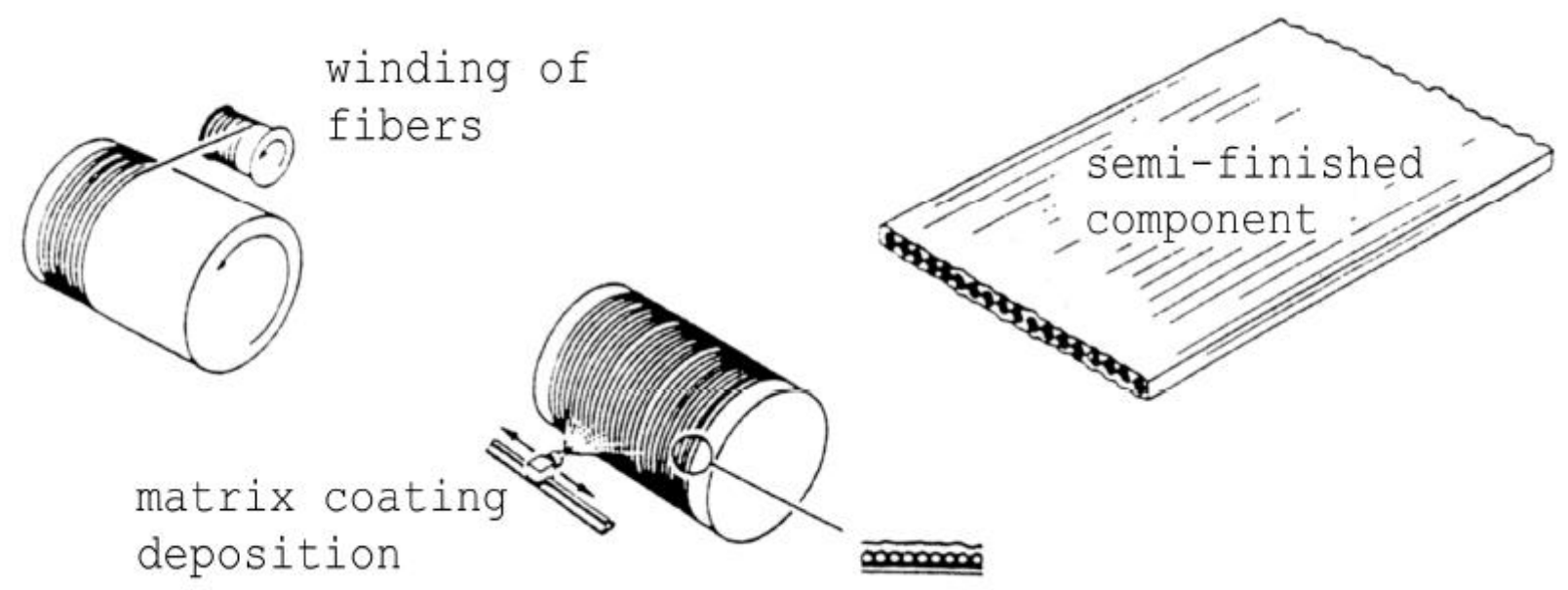

Fig. 7: Manufacturing process of UD fiber reinforced metals by thermal spraying [22]

Manufacturing of carbon short-fiber reinforced aluminum coatings for tribological (wear protection) applications was performed by Hoffmann et al. [23] by agglomeration of short-fibers with Al 99.5 powder and vacuum plasma spraying of the agglomerates, or alternatively, wire flame spraying with cored wires that had the agglomerates as a filling. These experiments resulted in porous, brittle composite coatings with a very low fiber content of ca. 1-2 vol\% due to fiber loss during spraying.

However, these experiments showed that thermal spraying is suitable to deposit a broad variety of metal and also cermet matrix materials on fiber substrates. Furthermore, it is possible to spray metals on fiber materials that are sensitive to thermal degradation or chemical reaction. Thereby, all available thermal spray techniques can be applied for fiber coating in general, whereas due to the high kinetic impact of the supersonic gases, the High-Velocity Oxy-Fuel technique (HVOF), or supersonic flame spraying, will not be applied. In contrast, plasma spraying in vacuum (VPS) or under atmospheric conditions (APS) is a suitable technology as well as wire flame spraying and twin-wire electric arc spraying, which was applied in this work.

For twin-wire electric arc spraying, the melting temperatures in the electric arc are approx. 4,000$5,000{ }^{\circ} \mathrm{C}$, while the temperature of the $\mathrm{Al} 6 \mathrm{Si}$ melt is in the region of $2,000{ }^{\circ} \mathrm{C}$ [17]. Although the melting points of the coating materials are in some cases much higher than the decomposition temperature of the substrates, fiber woven fabrics can be coated without any damage to the individual fibers, if the process parameters are adapted carefully in order to limit heat transfer to the fibers [24, 25]. Alternatively, high temperatures can be avoided by the application of cooling techniques, using e. g. compressed air for coating and substrate cooling as well as simultaneous removal of dust from the surface. In addition, the fast solidification and cooling of the small TS droplets almost completely prevent chemical reaction at the interface between the substrate and the coating.

By using simultaneous cooling and high relative speed between the coating jet and the fibers, the thermal load on the substrate can be limited to temperature levels in the range of $50-150{ }^{\circ} \mathrm{C}$ ( $\max$. $220^{\circ} \mathrm{C}$ for time periods $<0.1 \mathrm{~s}$ ). The resulting surface temperature for different cooling systems was measured by means of an infrared camera (Varioscan InfraTec ID, Dresden, Germany) during coating deposition on UD continuous carbon fibers wound on a cylinder. Lowest surface temperatures can be reached by the application of cooling nozzles attached on both sides of the 
spray torch and additional stationary cooling, see Fig. 8. Further limitation of the thermal load on UD fibers or fiber fabrics can be reached by an adapted torch path and torch kinetic that enables longer cooling periods.

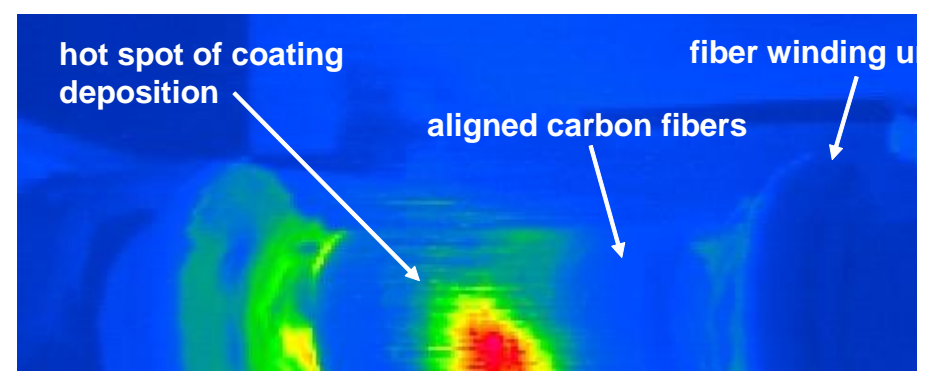

Fig. 8: Thermographic (IR) image of the surface temperature distribution during twin-wire electric arc coating of wound UD carbon fibers, showing a maximum temperature of $92{ }^{\circ} \mathrm{C}$

Thermal spraying enables the production of fiber reinforced composites with different fiber volume content by variation of the coating thickness. However, this is only possible within a certain range, because residual stresses increase with coating thickness, resulting in crack formation and coating delamination. Moreover, residual stresses can lead to deformation of coated prepregs (which can also be applied for prepreg manufacturing in case of UD reinforcements see below). For optimized trimming and lamination, coating thickness and residual stress distribution have to be well balanced in order to obtain flat fiber prepregs for unidirectional and woven fiber fabric reinforcements after coating. Fig. 9 shows a carbon fiber fabric with a thick (ca. 200-250 $\mu \mathrm{m}$ ) coating of Al 6Si alloy that was applied via twin-wire electric arc spraying. The coating wetted the carbon fibers well and penetrated into first fiber layers. Individual carbon fibers were surrounded by the alloy. No fiber damage is visible. However, the metal layer shows some porosity that has to be removed during the densification and forming process.

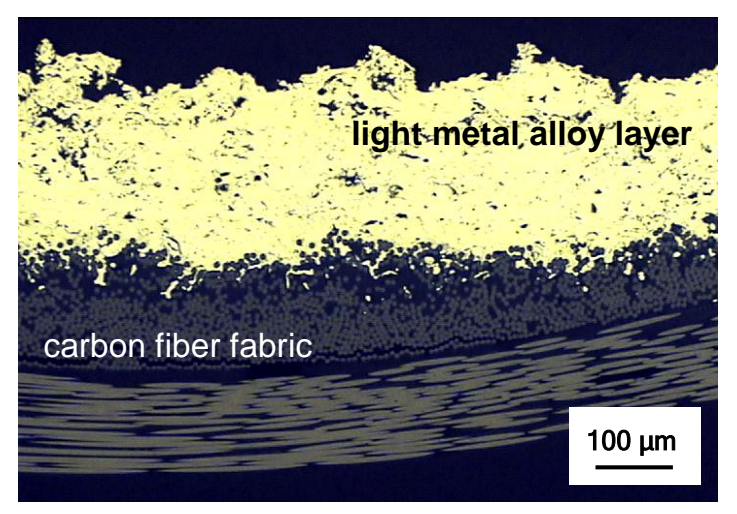

Fig. 9: Microstructure of an $\mathrm{Al}$ 6Si twin-wire electric arc coated carbon fiber fabric before heating (woven structure, fibers in the middle layer perpendicular to the cross section)

\section{Thixoforging of TS-Prepregs}

The use of semisolid impregnation of coated and laminated fiber fabrics can solve the problems related with long-time exposure of sensitive fiber materials to liquid melts. The metal has to infiltrate only a single fabric layer, and therefore, the flow paths are very short. This leads to short 
processing and cycle times and low mechanical loads on the fibers. Additionally, the semisolid state of the matrix alloy reduces fiber damage due to chemical reaction with the melt, the high content of solid phase reduces shrinking rate and residual stress formation, and the fiber volume content of the MMC can easily be tailored by the coating thickness. The thickness of the final component can be adapted by the number of thermal spray prepregs that are laminated.

The complete process chain for light metal MMC processing consists of fiber fixation and prestressing, fiber coating with the matrix alloy, trimming of the TS prepregs 2-dimensionally to the shape of the component, accumulation or stacking of trimmed prepregs to the necessary volume of the final component, reheating and thixoforging, see Fig. 10.

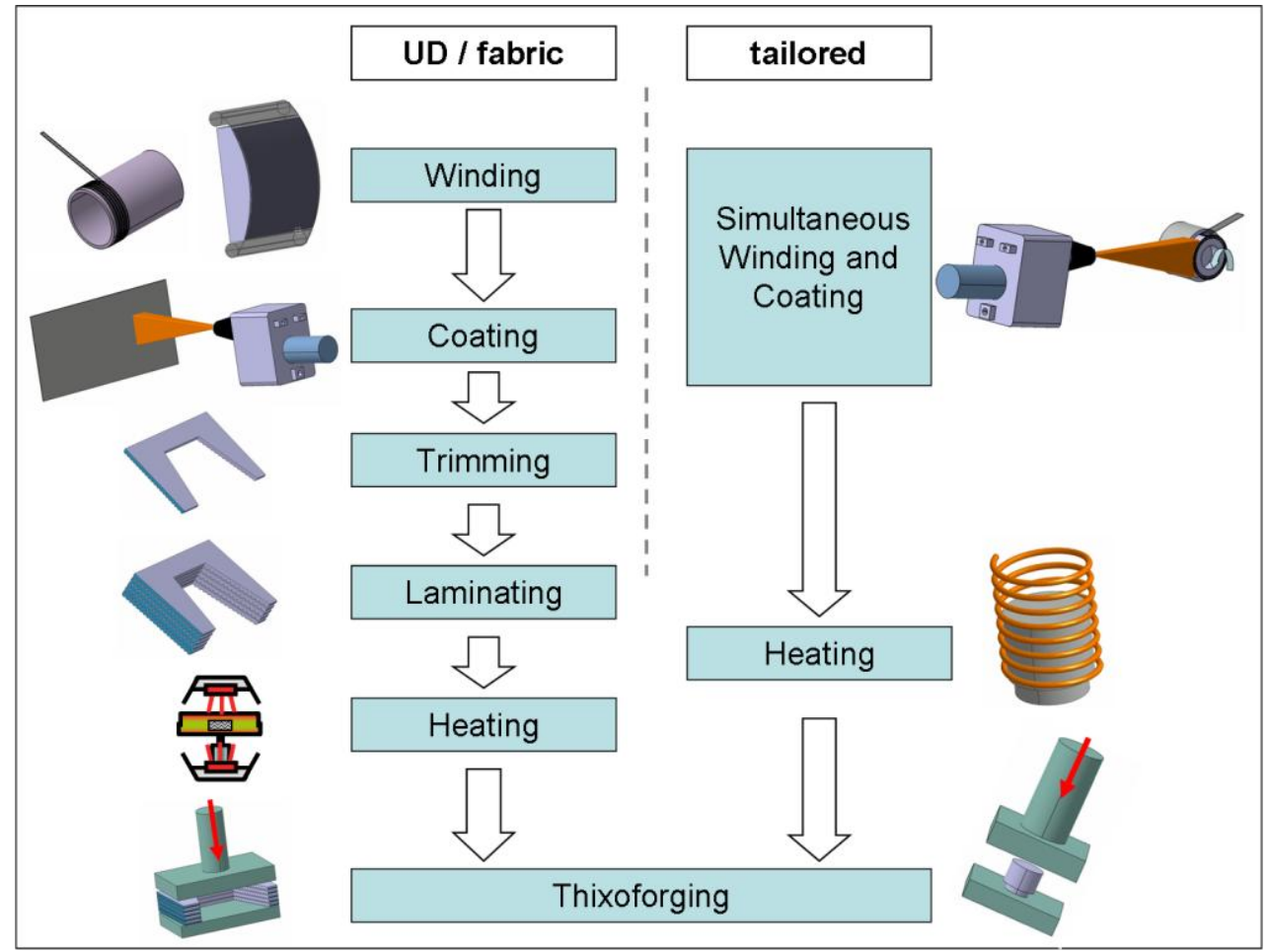

Fig. 10: Process chain for the manufacturing of fiber reinforced MMC components by thermal spraying and thixoforging

For continuous deposition with appropriate fiber tension, different methods were developed, depending on the structure of the reinforcement. Woven fiber fabrics are coated in a continuous process during winding of the cloth from one coil to the other, thus being able to produce large quantities of prepregs. Thereby, the process parameters have to be well-adapted to avoid large residual stresses in the fiber/coating composite with resulting prepreg deformation that would hinder coiling and later processing of the prepreg material.

In contrast, for UD continuous fiber reinforcement, the fibers are wound and stretched on a cylinder by using automated devices. Coating application by twin-wire electric arc spraying is done in an uncoupled, parallel cycle. Finally, the coated UD fibers are removed from the cylinder, forming flat prepreg sheets by deformation (from the cylindrical to the flat shape) due to residual stresses in the layer compound. As a consequence, the size of the cylinder which is used for fiber winding has to be adapted to the residual stresses in the prepregs, which depend on the coating thickness and on the heat and mass transfer during coating (maximum temperature of the surface, cooling system, speed of the torch, number of torch transitions etc.).

A similar method is applied for tailored, circular continuous fiber reinforcement. However, for local inclusion of fibers into solid light metals, the fibers are coated simultaneously during winding, see Fig. 10. Thereby, the required coating thickness for complete fiber impregnation has to be applied in one transition of the thermal spray jet. Hence, fiber spreading devices, pre-spread fiber 
tapes or thin tapes of fiber monolayers have to be applied, and the fiber winding speed has to be synchronized with the material deposition rate of the coating process.

The different methods for prepreg manufacturing will be described in more detail in the following paragraphs.

The piled prepregs are heated to the semisolid temperature for thixoforging, i. e. $577-590{ }^{\circ} \mathrm{C}$ for $\mathrm{Al} 6 \mathrm{Si}$, providing a liquid fraction of $40-60 \mathrm{vol} \%$ [15]. For material reheating, different methods can be applied, which are convective heating (in an oven under nitrogen atmosphere), infrared (IR) heating, or inductive heating. However, in order to reach the required temperature window for semisolid processing in short time to avoid a change in the material's microstructure, a large heat transfer has to be provided by the heating method. In a convective oven, realization of a sufficiently high heat transfer is difficult. On the other side, inductive heating, which is the most suitable method for billet-shaped semifinished material, is difficult for thin-walled, plate-shaped, fiber reinforced material. Therefore, short wave infrared heating with high-power IR radiators was applied in the present work for reheating of the prepreg materials prior to thixoforging.

For the thixoforging process, a hydraulic, uniaxial high-speed press was used with a maximum forging and locking pressure of $5,000 \mathrm{kN}$ and a maximum punch speed of $800 \mathrm{~mm} / \mathrm{s}$. The high punch speed guarantees appropriate thixotropic behavior of the matrix material, which rapidly cools during transfer from the heating device to the press, but also in the die as a result of heat transfer from the prepregs. The die was heated to a temperature of $450{ }^{\circ} \mathrm{C}$ in order to limit early cooling and solidification of the material, which leads to an increase in the viscosity of the material and the shear stresses, and finally, to damage or disarrangement of the fibers. The complete forging stroke with an adapted speed profile (fast closure of the die and slow densification to prevent fiber damage) lasted $20 \mathrm{~s}$ [25].

During thixoforging, the spray coated, semisolid alloy infiltrates the gaps, or porosity, in-between the fibers simultaneously to the forming process. The resulting MMC is completely infiltrated and has no residual porosity, see Fig. 11 [14]. Hence, a dense MMC with minimized fiber damage is produced. Fig. 12 shows the microstructure of a composite consisting of 18 layers of carbon fibers coated with about $125 \mu \mathrm{m}$ of $\mathrm{Al} 6 \mathrm{Si}$ matrix alloy. The fibers are oriented bi-directional in $0 / 90^{\circ}$ direction and perpendicular to the applied force during the forging process. The good wetting and complete infiltration of the metal matrix material into the fibers was experimentally determined. The single fibers show no deformation or other mechanical damage. During the sample preparation, the aluminum matrix partially delaminated from the surface near fibers oriented parallel to the investigated cross section, see Fig. 12 (fiber bundles in-plane with the image). This may be an indicator of low fiber matrix interface adhesion.

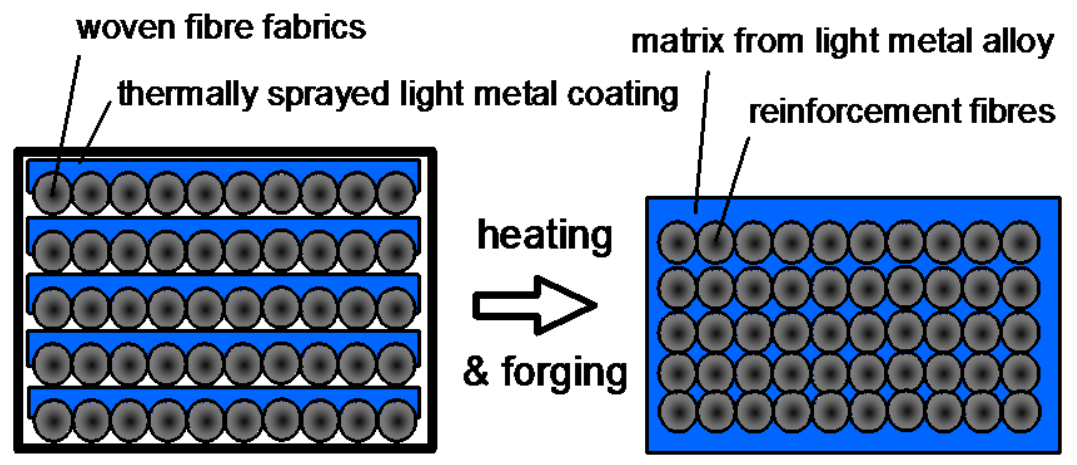

Fig. 11: Schematic process of TS prepreg piling and densification to final MMC components

Experimental evaluation of a MMC material that was thixoforged at $580{ }^{\circ} \mathrm{C}$ (similar to Fig. 12) also showed only minor chemical reaction (and thus damage) at the fiber/matrix interface. In order to 
obtain high resolution images of the fiber/matrix interface, transmission electron microscopy (TEM) was applied. Therefore, a thin cross section of a carbon fiber and the surrounding $\mathrm{Al} 6 \mathrm{Si}$ matrix was prepared by FIB sputtering, see Fig. 13 [26, 27]. TEM analysis of the interface region in that cross section discovered the presence of several small precipitates with diameters in the region of $50 \mathrm{~nm}$ (Fig. 13). These precipitates were particularly found at triple points, where grain boundaries of the matrix intersect with the fibers (region, where the liquid fraction of the semisolid metal was in contact with the fiber surface). Precipitates of small size and round shapes as shown in Fig. 13 may be uncritical for composite mechanics.
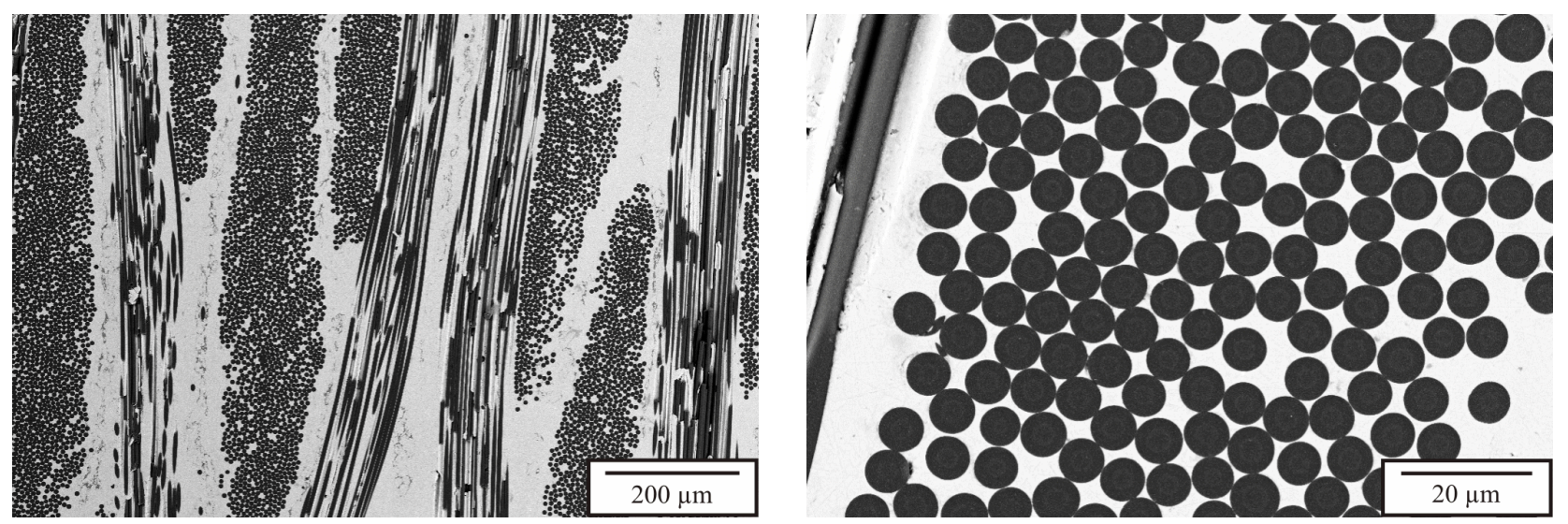

Fig. 12: Microstructure of thixoforged Al 6Si MMC with woven carbon fiber reinforcements from TS prepregs, showing complete infiltration without fiber damage
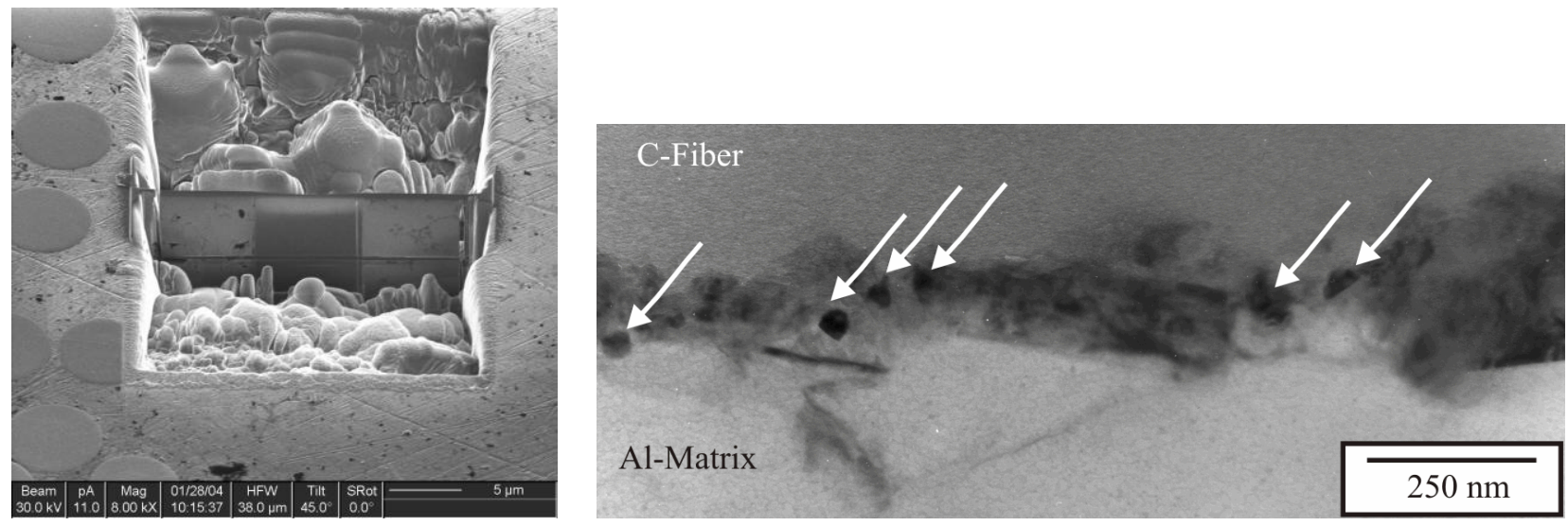

Fig. 13: FIB-preparation of TEM-lamella $(\mathrm{d}=100-200 \mathrm{~nm})$ and TEM image of the carbon fiber / aluminum matrix interface; several precipitations with a size of about $50 \mathrm{~nm}$ can be observed

However, the precipitates can also grow up to sizes of $300 \mathrm{~nm}$, see Fig. 14, where the precipitate was large enough to determine the crystal structure by selected area diffraction (SAD). The SAD pattern indicates clearly aluminum carbide $\left(\mathrm{Al}_{4} \mathrm{C}_{3}\right)$ formation, which obviously can originate from reaction of the fibers with the matrix. The particle depicted is shown in a $<100>$-orientation and exhibits several twins perpendicular to the c-axis (also visible from the diffraction spots). The two very bright diffraction spots can be attributed to the aluminum matrix material.

This sharp-edged and brittle aluminum carbide crystal on the fiber surface could reduce the mechanical properties of the MMC significantly. However, due to the low processing temperatures and short cycle times of the thixoforging process, the amount of these precipitates is nearly negligible and should not have a large influence on the mechanical properties.

The components that were manufactured by thixoforging in this work were rectangular, flat plates of the dimensions $150 * 110 * 4 \mathrm{~mm}$ for the manufacturing of mechanical characterization 
samples, and plate-shaped sample components with stiffening corrugations, or crimps, in order to analyze the possibility of the fibers to follow edges and cavities in the die, see Fig. 15.

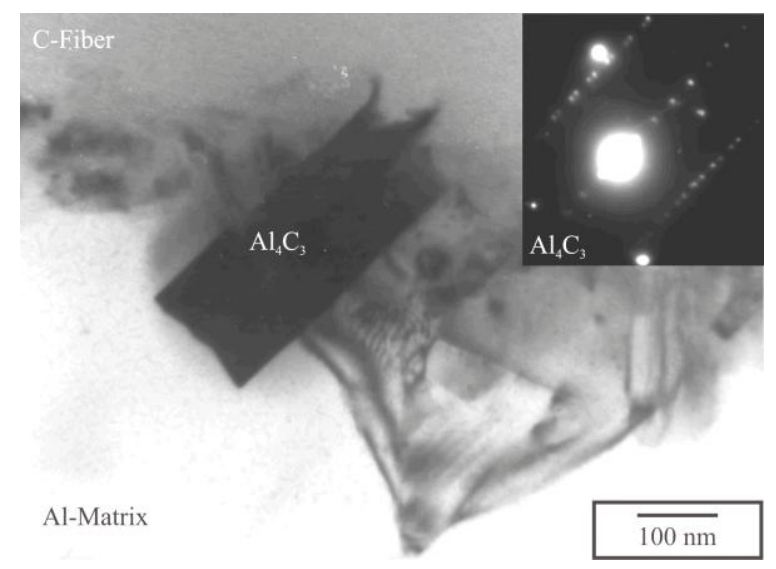

Fig. 14: Selected area diffraction of $\mathrm{Al}_{4} \mathrm{C}_{3}$ precipitation at the C-fiber/Al $6 \mathrm{Si}$ matrix interface

Due to the high punch speed necessary to avoid cooling and solidification of the matrix, the fibers did not follow the corrugations without being sheared partially. As a consequence, due to the fact that the die can not be heated up to thixoforging temperature of the semifinished material (which would avoid the material to solidify at all), there are two possibilities to increase fiber flow ability in complex die geometries:

- faster transfer of reheated prepregs to the die in combination with further optimization of the punch speed profile, or

- adaptation of prepreg geometries to allow for complex component geometries (tailoring of fiber reinforcements).

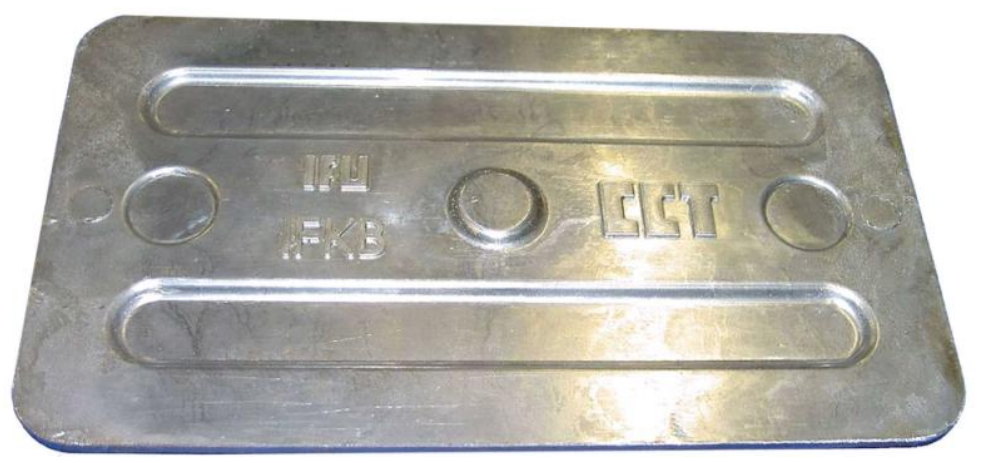

Fig. 15: Thixoforged, woven carbon fiber reinforced MMC with Al 6Si matrix (214*124 mm)

\section{Short Fiber Reinforced Aluminum MMC}

Metal matrix composites (MMC) with discontinuous reinforcement in the form of particles, whiskers or short fibers can be attractive alternatives to continuously reinforced material, because they show more isotropic material properties as well as, generally, lower production and process cost. Thereby, the properties of short fiber reinforced MMC are in-between continuous fiber and particle reinforced MMC [28].

Experimental Setup. As matrix material, wires of the aluminum-silicon alloy Al 6Si (EN AW4043AA, AA 4043A) were chosen with a chemical composition of 4.85-5.20 wt\% $\mathrm{Si}, 0.15$ $0.17 \mathrm{wt} \% \mathrm{Fe}$, and $\mathrm{Al}$ balance. The aim was the comparison of the final mechanical properties to the 
important cast alloys for automotive applications, Al Si7Mg (EN AC-42000, AA A356) and Al Si7Mg0.3 (EN AC-42100, AA A357.0). Material properties of the three aluminum alloys are given in Tab. 1. The density is in the region of $\rho=2.65-2.70 \mathrm{~g} / \mathrm{cm}^{3}$ for all alloys. The $\mathrm{Al} 6 \mathrm{Si}$ material was delivered by Sulzer Metco Europe GmbH, Hattersheim (Germany). The matrix material was sprayed on carbon short fibers that were prepared as fiber paper, or rather fiber fleece, in order to provide them with a suitable mechanical stability to withstand the load of the moving gas jet during coating. The fiber fleece with a mass per unit area of $200 \mathrm{~g} / \mathrm{m}^{2}$ was manufactured by elutriation of carbon short fibers (HT type, 3-6 mm individual fiber length, properties given in Tab. 1) and stabilization with a polymer binder at Frenzelit-Werke GmbH \& Co. KG, Bad Berneck (Germany). The coated short fiber prepregs were cut, piled, reheated, and densified by semisolid forging to plate shaped sample components. The resulting MMC material was tested by 4-point bending experiments and characterized by microscopy and SEM.

In order to derive different fiber volume contents of the sample components, the coating thickness was adapted to a suitable weight per unit area for specific fiber contents during matrix deposition. In this way, tailored prepregs with fiber volume contents of $\mathrm{f}=23,36$, and $45 \mathrm{vol} \%$ were manufactured. The thermal spraying technique applied was twin-wire electric arc spraying. The spray parameters are given in Tab. 2. Due to the low mechanical stability of the fiber fleece, low deposition rate and atomization air pressure were chosen. The direct process parameters of the spray particles, i. e. particle velocity and particle temperature, were measured using the SprayWatch $^{\circledR}$-2i Standard system from Oseir Ltd., Tampere (Finland).

Table 2: Parameters of the twin-wire electric arc process

\begin{tabular}{llllll} 
& Voltage, & Feed Rate, & Air Pressure, & Particle Velocity, & Particle Temp., \\
& $\mathrm{U}(\mathrm{V})$ & $\mathrm{f}(\mathrm{m} / \mathrm{min})$ & $\mathrm{p}(\mathrm{bar})$ & $\mathrm{v}_{\mathrm{p}}(\mathrm{m} / \mathrm{s})$ & $\vartheta_{\mathrm{p}}\left({ }^{\circ} \mathrm{C}\right)$ \\
\hline Machine parameters & 22.0 & 3.3 & 3.0 & - & - \\
Direct spray parameters & - & - & - & $100-110$ & $2,400-2,500$ \\
\hline
\end{tabular}

The matrix material was sprayed on the fiber fleece by a meander movement, whereby the spray torch was guided by a six axis industrial robot. The surface of the fiber fleece and coating was cooled during deposition and afterwards by a compressed air jet, which also led to a cleaning of the surface from spray dust and residues. During coating deposition, the fleece was fixed in a metal frame and mounted on a sample holder rack to give mechanical support. For future applications with the aim on higher material batches, a continuous coating method has to be developed, similar to the continuous winding and coating installation that was developed for long fiber fabrics in earlier work $[13,25]$. Thereby, the limited mechanical stability of the short fiber fleece that is mainly due to the polymer binding agent has to be taken into account.

Thixoforging of sample components from short fiber prepregs was made with the equipment and process parameters in analogy to the description in chapter "Thixoforging of TS-Prepregs". The sample plates, from which specimen for microstructural and mechanical characterization were prepared, had dimensions of $150 * 110 * 4 \mathrm{~mm}$.

Characterization of Short-Fiber Reinforced MMC. From the resulting, thixoforged MMC sample plates, bending specimen were prepared and tested by 4-point bending according to EN 658-3:2002 [29]. Thereby, it has to be taken into account during comparison of the results with other materials, that bending experiments generally result in slightly higher strength values than tensile experiments. The Young's moduli of the materials with different fiber content were derived from the stress-strain diagrams of the bending experiments by fitting the tangent on the initial, linear elastic part of the curves. The samples were analyzed by light optical microscopy and SEM after matrix deposition (as-sprayed) as well as after densification. Additionally, the fracture surfaces of the bending specimen were examined by SEM. 
Results - Microstructure. During thermal spray coating of the fiber fleece, the matrix material had a good bonding to the surface of the fleece but was not infiltrating in-between the fibers, as was demonstrated for fiber fabrics in earlier work [14]. In Fig. 16, left, the heterogeneous, splat-like structure of the wire arc coating can be seen on the surface of the fiber fleece. It is assumed that the infiltration during spray deposition was hindered by the polymer binder that forms a thin film on the fiber fleece. Therefore, the flow paths during thixoforging were larger than for woven continuous fiber prepregs. Nevertheless, the densification process led to complete infiltration of the fibers and dense MMC materials with a residual porosity of $\leq 0.5$ vol\% (optical measurement), see Fig. 16, right.
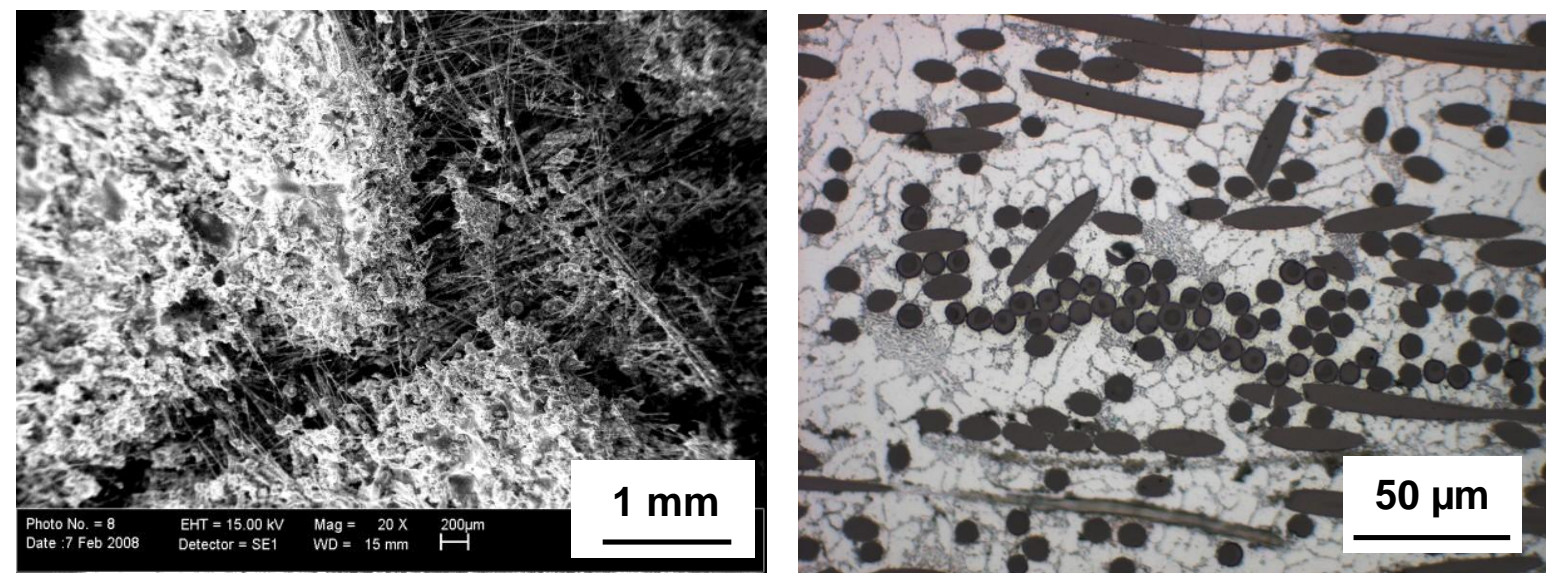

Fig. 16: SEM of Al 6Si matrix thermally sprayed on HT carbon fiber fleece (left); micrograph of Cfiber/Al 6Si-MMC, fiber volume content 35.0 vol\% (right)

Micrographs of the MMC (Fig. 16) show a nearly homogeneous, stochastic distribution of the carbon short fibers in the matrix alloy. The grains of the aluminum rich phase show a shape that is close to the globular grains of the thermally sprayed and reheated material, comp. Fig. 3 (right), while the grain sizes are larger due to the slow cooling process in the heated die, which supports grain coarsening. The eutectic phase, which is the liquid phase during semisolid forming, was collected in volumes up to $20 \mu \mathrm{m}$ in size, see Fig. 16, where the liquid was filling porosity inbetween the fibers that could not be filled during densification by the solid grains due to their size.

Because of grain coarsening at the component surfaces during densification, the matrix alloy accumulated at the surfaces depending on the matrix content, leading to a change in the fiber volume content inside the components. Therefore, the final fiber volume contents of the MMC sample plates were $\mathrm{f}=28.2,35.0$, and $38.8 \mathrm{vol} \%$. That means, the broader range of fiber volume contents of the prepregs was reduced during thixoforging.

Results - Mechanical Properties. Stress-strain diagrams of the 4-point bending experiments are given in Fig. 17 for the three different fiber volume contents. Thereby, the average curve and the best performing sample are displayed, respectively. The MMC material is generally lower in strain to failure than the matrix material $\mathrm{Al} 6 \mathrm{Si}$, with values below or equal to $0.8 \%$, and accompanied by an increase in yield stress at $0.2 \%$ strain. This is in good analogy to literature [2].

Results from the 4-point bending experiments for flexural strength, $\sigma_{\mathrm{fm}}$, and Young's modulus, E, are given in Fig. 18 with the absolute measured values for different fiber volume contents indicated. The Young's moduli of the MMC follow a nearly linear trend to higher stiffness for higher carbon fiber content. However, the measured Young's moduli are lower than theoretically predicted values by either an equal strain assumption for axial loading of continuous, aligned fibers (Voigt model), which leads to the rule of mixture (see Eqn. 1), or an equal stress assumption for transverse loading perpendicular to the fiber direction (Reuss model), which leads to the correlation in Eqn. 2. Thereby, the Voigt model describes a theoretical maximum value that can only be 
approached for unidirectional (UD) reinforcement with continuous fibers that are long enough to support the equal strain assumption [2]. The theoretically predicted MMC stiffness values for $\mathrm{f}=28.2,35.0$, and 38.8 vol\% by the Voigt and the Reuss model, with $\mathrm{E}_{\mathrm{M}}=70 \mathrm{GPa}$ (matrix) and $\mathrm{E}_{\mathrm{F}}=300 \mathrm{GPa}$ (fibers), are also given in Fig. 18.

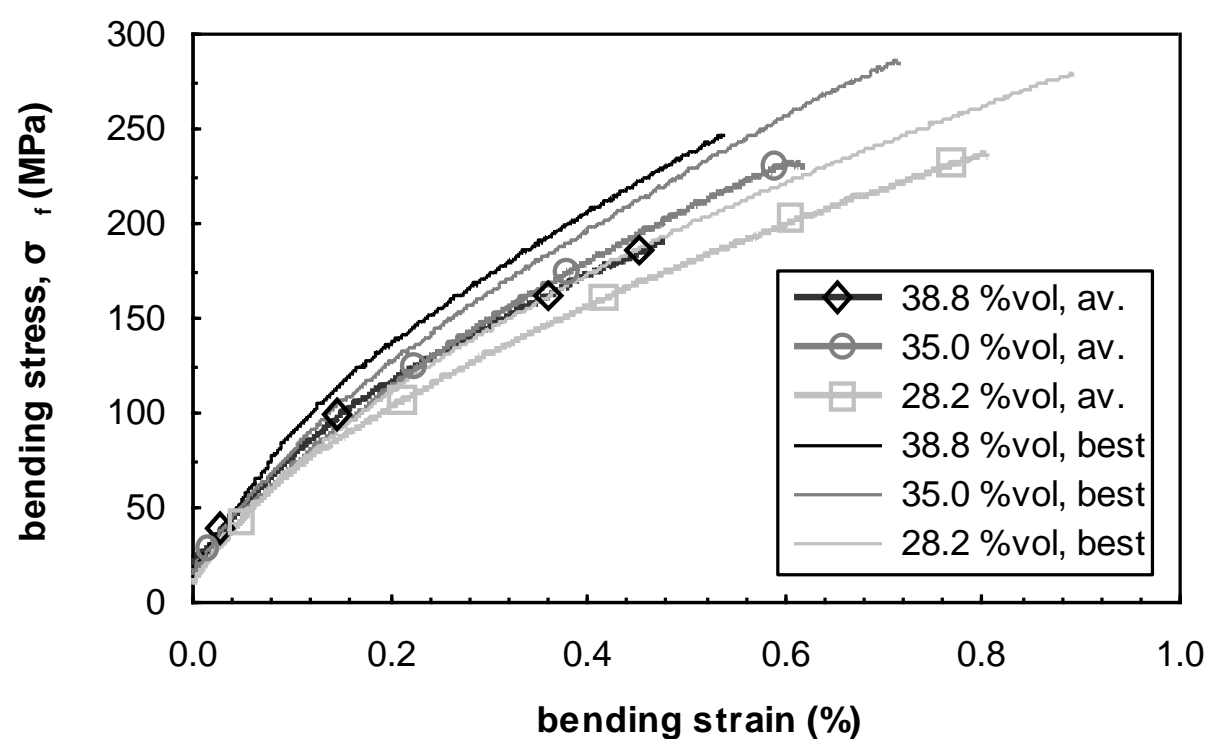

Fig. 17: Stress-strain diagrams of 4-point bending experiments for C-short-fiber/Al 6Si-MMC with different fiber volume contents

$$
E_{\text {Reuss,transversal }}=\left[\frac{f}{E_{F}}+\frac{(1-f)}{E_{M}}\right]^{-1}
$$

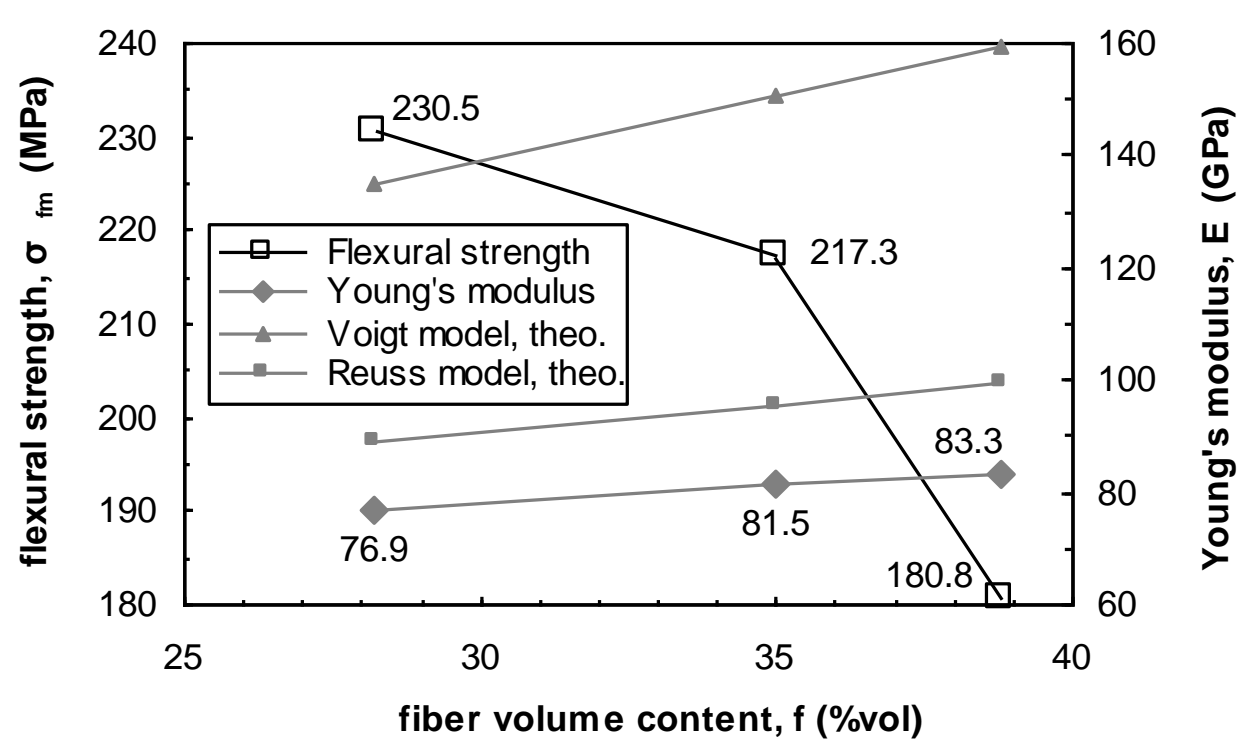

Fig. 18: Flexural strength, $\sigma_{\mathrm{fm}}$ (4-point bending), and Young's modulus, E, for C-short-fiber/Al 6SiMMC with $\mathrm{f}=28.2,35.0$, and 38.8 vol\%

The experimentally determined stiffness values should be lower than the predicted values by the rule of mixture, but higher than the predicted values by the equal stress method, because there is a statistical fiber orientation with fibers aligned in load direction and in transverse direction. However, the determination of Young's modulus from the tangent to the initial, linear elastic part of stress-strain curves derived from bending experiments is difficult due to the small proportional 
regime, and moreover, it is sensitive to failures due to settling phenomena in the measuring chain. This could be one reason for the low measured Young's moduli. Another reason could be insufficient fiber/matrix bonding strength, because in the case of interface debonding, the assumptions of equal strain or equal stress are suspended. This presumption is supported by the flexural strength results in Fig. 18, which show decreasing strength for increasing fiber content, whereas a rule of mixture approach for the strength leads to a positive correlation between fiber content and composite strength.

The fracture surfaces were analyzed by SEM and show extensive debonding of the transverse fibers without large plastic deformations, see Fig. 19. Moreover, the axial fibers also show interface debonding and pull-out effects in some areas, whereas in other areas, fiber fracture is close to the metal fracture surface and the matrix is deformed in load direction, as could be expected for MMC. These observations lead to the assumption that the thermally sprayed, reheated and thixoforged aluminum matrix is more brittle than the original $\mathrm{Al} 6 \mathrm{Si}$ alloy and the fiber/matrix bonding is weak, leading to early crack formation and a reduction in the composite's mechanical properties.
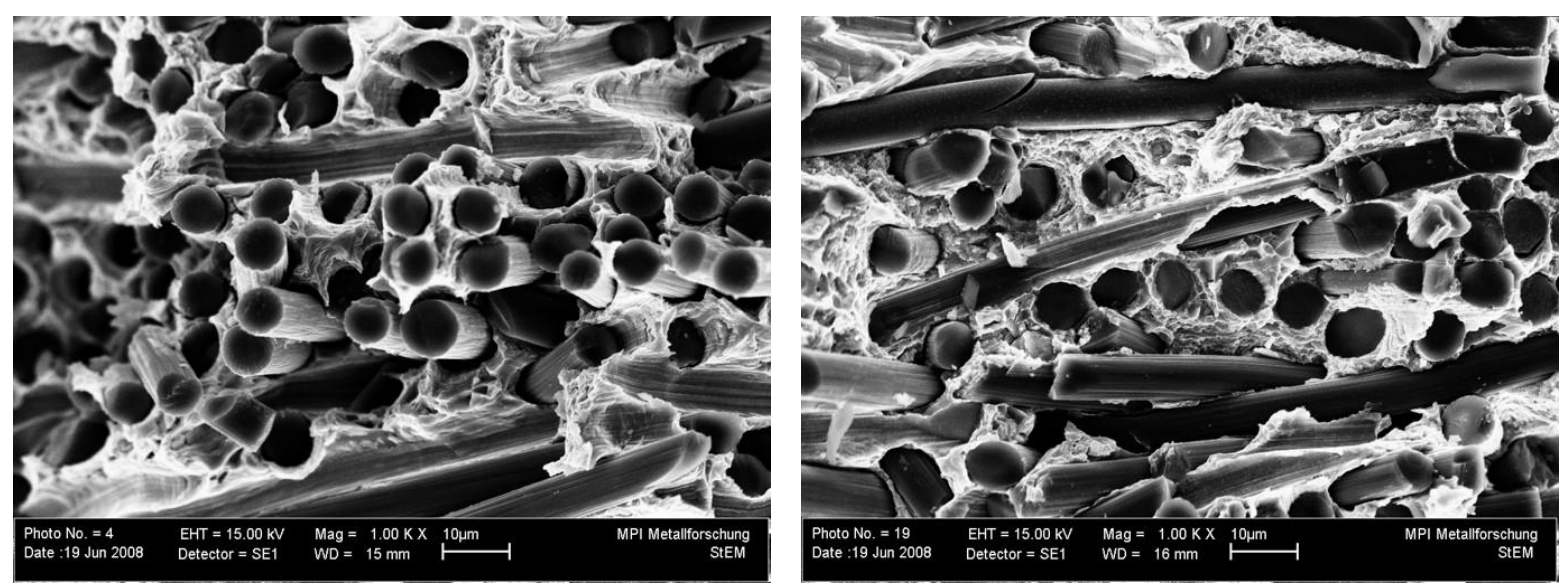

Fig. 19: SEM of fracture surfaces from 4-point bending experiments; fiber volume contents are $28.2 \mathrm{vol} \%$ (left) and 38.8 vol\% (right)

\section{Continuous 2D Fiber Reinforced Aluminum}

Two-dimensional fiber structures are required for components subjected to complex mechanical load in large area applications. In this case, textile woven fabrics are used as basic material for coated prepregs. Carbon fiber cloth of HT, HM and IM type C-fibers were used along with fabrics of SiC (Nicalon), alumina (Nextel 610), and Tyranno ceramic fibers for comparison reasons. The matrix alloy was $\mathrm{Al} 6 \mathrm{Si}$, which was applied by twin-wire electric arc spraying.

Coating of 2D Fiber Textiles. In order to apply thermal spray techniques to temperature sensitive, flexible fiber structures, two main difficulties have to be considered. First, the fabric has to be fixed and stretched to give it sufficient mechanical support. Second, the kinetic and thermal energy of the molten particle jet can mechanically and chemically damage the fibers and their woven structure, which has to be avoided by an adapted process control.

For fixation and stretching of fiber fabrics, tentering frames can be applied for experiments on a laboratory scale. However, in order to demonstrate a possible industrial scale processing, a special winding equipment was designed, see Fig. 20 [10, 25], which can bear coils of woven fiber cloth up to $1,500 \mathrm{~mm}$ in width that are fed continuously over a convex shaped deflector providing the coating region. Load cells inside the drive rolls of the winding equipment control the tension of the stretched fabric. If elongation or contraction of the fabric due to thermal expansion occurs, electric drives will compensate the change of tension within a control loop, and thus enable feeding and 
coating of the fabrics with constant, pre-defined prestress from "coil to coil". The convex coating table is placed on an exhaust box with aspiration vents and a perforated facing, see Fig. 20. Via these aspiration vents, the box and the coating area of the table can be set under low pressure. Thereby, the fabric is fixed and the continuous airflow through the fabric cools the fibers and cleans them from overspray particles during coating. The cooling and cleaning effect is intensified by compressed air cooling nozzles that are laterally attached at both sides of the spray torch.

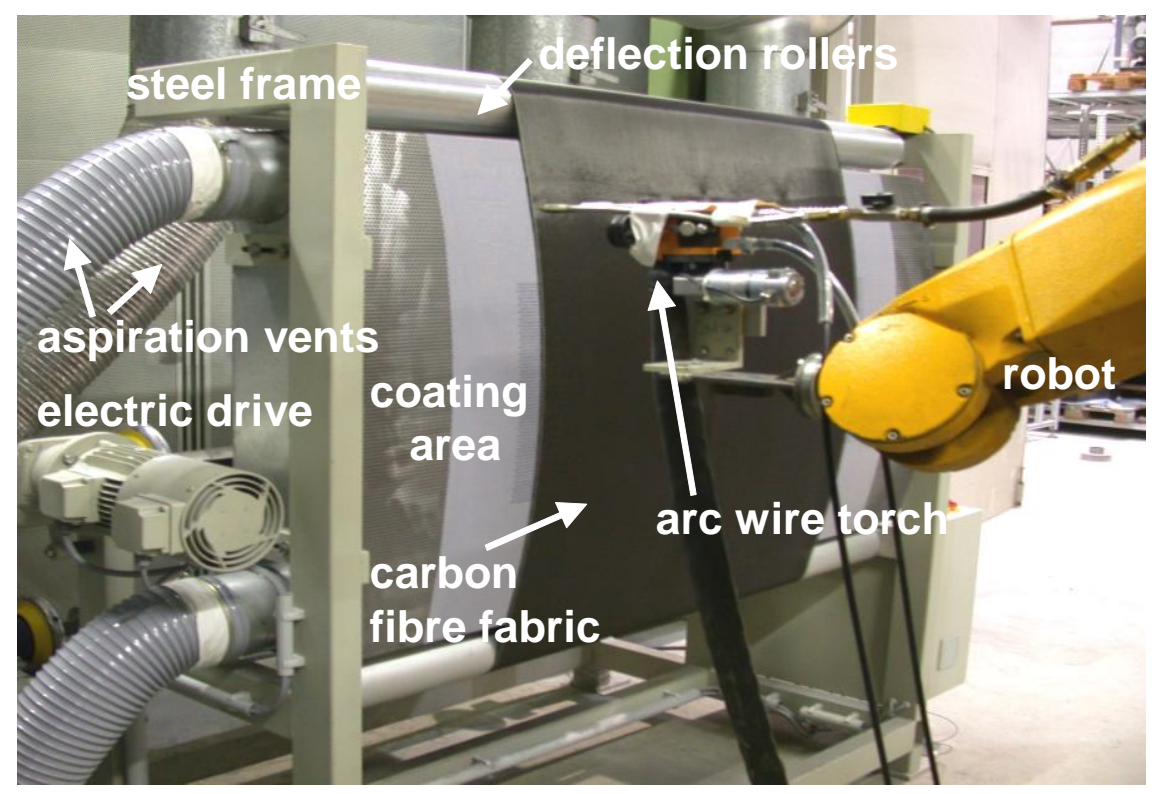

Fig. 20: Winding equipment for continuous coating of woven fiber fabric coils [19, 20]

Besides the cooling system, the relative speed between the fabric and the particle jet should be high in order to keep the thermal and kinetic load on the fabrics as low as possible. The trajectory of the arc wire torch is performed by a 6-axis robot system. In order to obtain a high relative speed between the torch and the fabric as well as to completely cover the surface during coating, the torch moves in a meandering coating motion. This meander can be adjusted for non-stop or incremental coating. A continuous fabric feed process has advantages for robot programming and control unit synchronization of the different system modules. However, if coatings can only be realized by two or more passes (e. g., because of large coating thickness or reduction of heat transfer), an incremental operation mode has to be used.

If non-stop winding is applied, the winder feeds the fabric with a well-adapted speed inside the coating area where the robot performs a uniform in-line coating. Both winding speed and robot movement have to be synchronized in such a way that the meander distance and the relative speed of the fabric and the torch are well-defined. This problem is solved by an "x-shaped" movement of the robot and an adjusted winder movement, see Fig. 21 (left).

If the incremental operation in cycles is required, the winder provides a desired length of fabric inside the coating area and pauses, keeping the pre-defined tension within the fabric while the robot is coating a specified length of the fabric in a meander movement, see Fig. 21 (right). Both coating modes can be combined in a permanent winding and a more complex movement of the robot to achieve an optimized heat and mass transfer to the fabric. To coat carbon fiber fabrics for the production of MMC, the non-stop winding is preferred. Due to the high deposition rate of twin-wire electric arc spraying, it has the advantage of a fast and easy process.

This continuous coating system was developed due to the fact that MMC require a high fiber volume content in order to achieve mechanical properties (mainly in terms of stiffness) that justify the higher production costs, and typical components (e. g., plates) consist of up to 80 reinforcement fabric layers. Therefore, a production line that is suitable to supply prepreg material in the quantity 
range of some $10 \mathrm{~m}^{2} /$ hour is required. The coated prepregs can be trimmed in a subsequent step by $\mathrm{NC}$ cutting systems, providing reduced material wastage.
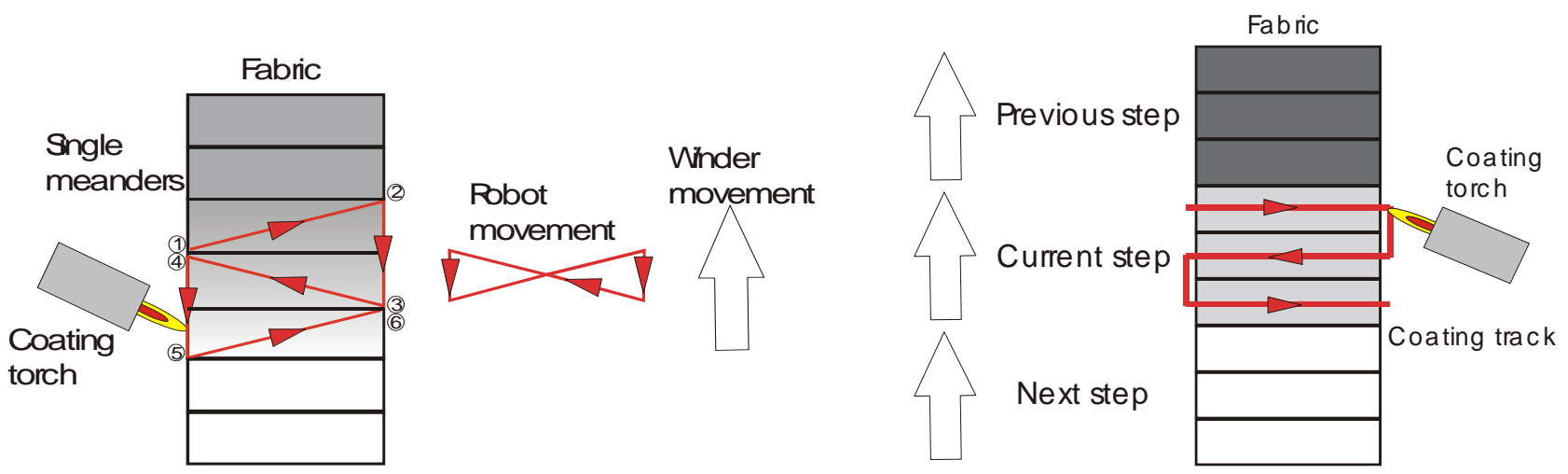

Fig. 21: Coordination of winder and robot movement during non-stop winding (left) and during incremental winding in cycles (right) [20]

Results - Mechanical Properties. To characterize the mechanical properties for different types of 2D reinforcement fibers, 4-point bending experiments were made on samples that were prepared from thixoforged plates. Fig. 22 shows the flexural strengths of $\mathrm{Al} 6 \mathrm{Si}$ with $2 \mathrm{D}$ reinforcement of Cfibers (HT, IM, and HM type) with a fiber volume content of $\mathrm{f}>50 \mathrm{vol} \%$, Nicalon fibers with $\mathrm{f}=60 \mathrm{vol} \%$, Tyranno fibers with $\mathrm{f}=40 \mathrm{vol} \%$, Nextel 720 fibers with $\mathrm{f}=35 \mathrm{vol} \%$, and Nextel 610 fibers with $\mathrm{f}=25 \mathrm{vol} \%$. All applied fabrics had a fiber orientation of $0 / 90^{\circ}$. For comparison, strength values of $\mathrm{Al} 6 \mathrm{Si}$ alloy as thermal spray wire and as unreinforced, thermally sprayed and thixoforged matrix material were included in Fig. 22. These values for the unreinforced matrix alloy were determined by tensile testing.

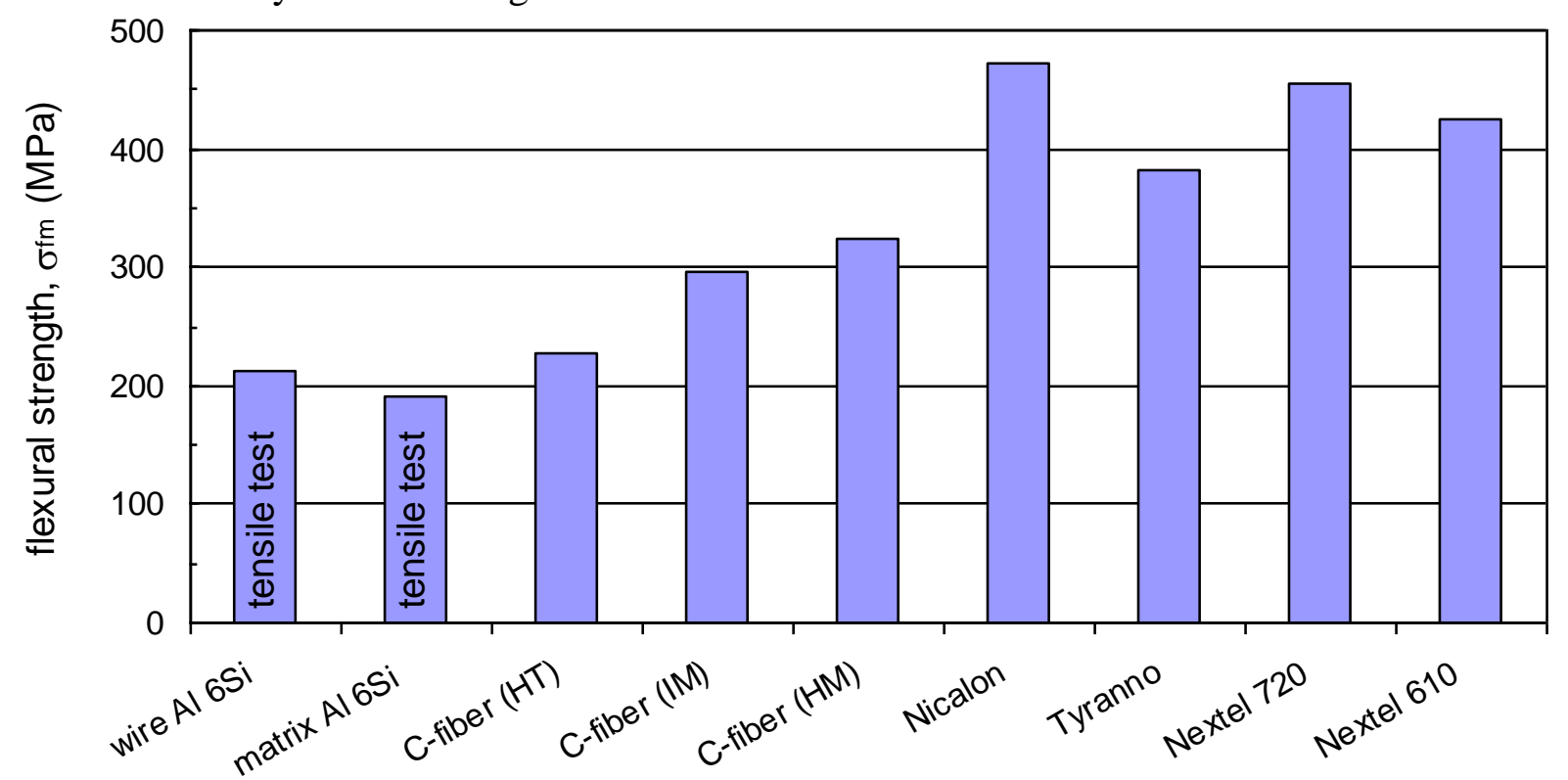

Fig. 22: Flexural strength, $\sigma_{\mathrm{fm}}$ (4-point-bending), of 2D fiber fabric reinforced $\mathrm{Al}$ 6Si (different fiber types and fiber volume contents) [19]

As a thermal spray wire, the Al 6Si material has a tensile strength of UTS $=213 \mathrm{MPa}$, while the tensile strength of the thermal spray deposited and thixoforged alloy is $190 \mathrm{MPa}$. However, the sample geometries and surfaces were different for the two tensile test series (with the wire being tested as raw material, while tensile test bars of the thixoforged material were machined from sample plates). As for the fiber fabric reinforced composite materials, the MMC with Nicalon 
reinforcement achieves the highest bending strength of $\sigma_{\mathrm{fm}}=471 \mathrm{MPa}$, which may be attributed to the high fiber volume content of $60 \mathrm{vol} \%$. In contrast, the Tyranno, Nextel 720 and Nextel 610 fibers with lower fiber volume content result in lower flexural strength, which are $381 \mathrm{MPa}$, $456 \mathrm{MPa}$, and $425 \mathrm{MPa}$, respectively. Nextel 720 fibers consist of $85 \% \alpha$-alumina and $15 \%$ silica $\left(\mathrm{SiO}_{2}\right)$, whereas the pure $\alpha$-alumina Nextel 610 fibers are more suitable for the application in MMC. Therefore, the lower strength of the Nextel 610 reinforcement must be attributed to the lower fiber volume content.

Aluminum reinforced with carbon fiber fabrics has bending strengths of $227 \mathrm{MPa}$ for HT carbon fiber cloth, $295 \mathrm{MPa}$ for IM carbon fibers and $323 \mathrm{MPa}$ for HM carbon fibers. That means, the composite strength is related to the fiber's modulus and not to their absolute strength as monofilaments (where the HT type fiber yields the highest values). A possible reason for this is that with decreasing stiffness, earlier fiber/matrix debonding leads to decreasing composite strength, which would not occur for strong interface adhesion between fiber and matrix alloy. However, fracture surface investigation showed brittle fracture behavior with fiber pull-out that supports this assumption. Summarizing the relatively low strength values and brittle behavior, the focus of future research has to be on an improved fiber/matrix interface.

\section{Continuous UD Fiber Reinforced Aluminum}

The manufacturing of prepregs for unidirectional (UD) fiber reinforcement requires the parallel alignment of continuous fibers with a uniform thickness of the fiber bundles and fixation of the fibers in a prestressed condition to avoid fiber dislocation during the coating process due to kinetic impact of the spray gases and coating material. Therefore, prior to the coating process, the fibers are coiled on a cylindrical workpiece with adapted dimensions. Spreading and accurate alignment of the fibers are necessary to achieve homogeneous thickness of the later prepreg. Coating application by means of twin-wire electric arc spraying with simultaneous cooling of the surface is performed in a second step of the process.

Experimental Setup for UD Fiber Reinforcement. For winding of the continuous fibers, a winding unit was developed with the focus on short cycle times during prepreg manufacturing, see Fig. 23. A stable aluminum frame provides the structural basis for different components. A friction brake unit at the rotational coil axis is used to control fiber tension during the winding process. The fiber tension can be adapted continuously. A fiber guide unit is used for parallel alignment of the fiber strand that can also be continuously varied in speed and horizontal range of the winding width. This fiber guide unit consists of several rolls for fiber strand control, fiber spreading, fiber deposition on the winding unit (cylinder) at a constant angle and for prevention of fiber strand drilling.

For fiber deposition and winding, cylinders of different size can be used. By adaptation of the cylinder diameter to the coating thickness, it is possible to produce flat fiber prepregs. After removal of the coated prepregs from the substrate cylinder and cutting them to the desired fiber length, the primary cylindrical shape deforms towards a flat geometry due to residual stresses which arise during coating deposition. A flat fiber prepreg structure reduces the handling effort in the subsequent processing steps. During the winding process, the cylinder's rotational speed has to be synchronized with the speed of the fiber guide unit. The speed ratio is responsible for the overlapping, which is an important factor to obtain a homogeneous fiber layer thickness and sufficient prepreg stability.

During coating deposition (after complete winding and fixation of the fibers to the cylinder), the relative speed between the fiber surface and the particle jet also depends on the rotational speed of the cylinder. Thus, the axial feeding rate of the spray torch has to be adapted to the cylinder's rotational speed in such a way as to achieve pre-defined coating parameters. The relative speed of 
the spray jet has to be optimized in order to keep the thermal and kinetic load on the fibers as low as possible and to minimize cycle times [13, 20, 25].

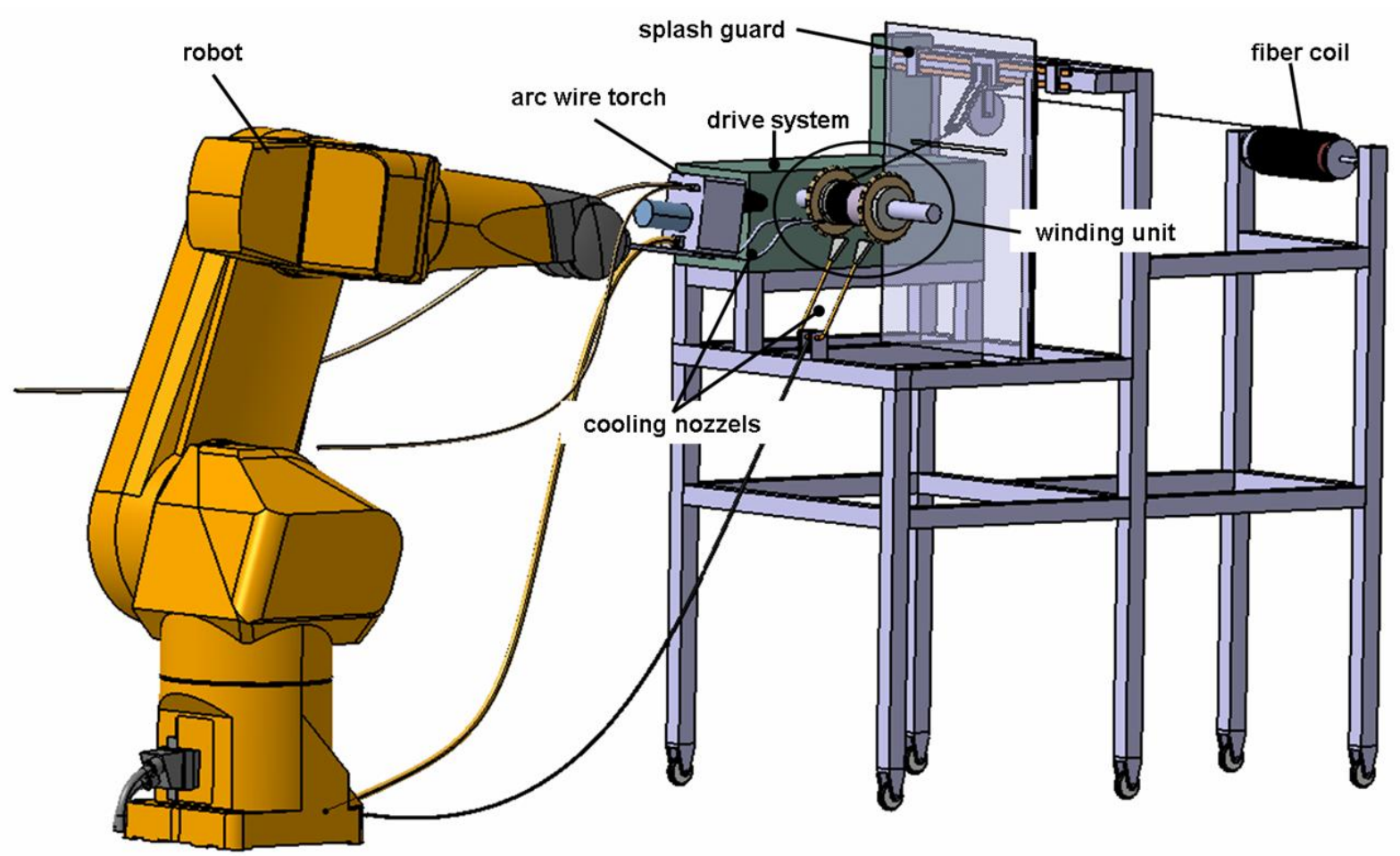

Fig. 23: UD fiber winding unit, twin-wire electric arc torch, and 6-axis handling robot

An efficient cooling system is required in order to control the thermal load, which affects the formation of microcracks and determines the final residual stress distribution in the composite. Therefore, four compressed air cooling nozzles are applied. Two of them are attached on both sides of the spray torch in order to clean the surface prior to coating deposition and to cool the coating directly after material deposition. The two additional nozzles are stationary fixed and directed towards the bottom side of the cylinder, leading to an additional cooling effect and an overall lower temperature of the composite during coating.

Results - Mechanical Properties. Similar to 2D reinforced MMC testing, thixoforged material samples for different fiber materials and continuous UD fiber architecture were analyzed by 4 point-bending experiments. Results for flexural strengths are given in Fig. 24, with unreinforced, thermally sprayed and thixoforged $\mathrm{Al} 6 \mathrm{Si}$ matrix material for comparison (unreinforced matrix material was tested by tensile testing, comp. Fig. 22). Fiber materials were basalt fibers with a fiber volume content of $\mathrm{f}=45 \mathrm{vol} \%$, carbon fibers (HT type) with $\mathrm{f}=40 \mathrm{vol} \%$ and $\mathrm{f}=50 \mathrm{vol} \%$, UMS type C-fibers with $\mathrm{f}=45 \mathrm{vol} \%$ (UMS: ultra-high modulus and strength; PAN-based fiber by Toho Tenax $^{\circledR}$ with $\mathrm{E}=395 \mathrm{GPa}$ and $\mathrm{UTS}=4560 \mathrm{MPa}$ ), and alumina fibers (Nextel type 610) with $\mathrm{f}=45 \mathrm{vol} \%$.

Compared to the flexural strength of fiber fabric reinforced $\mathrm{Al} 6 \mathrm{Si}$, the bending strengths of the UD fiber reinforced samples are higher. At 4-point-bending tests of the 2D MMC, only about half of the fiber volume contributes to the mechanical strength, due to the one-dimensional stress load during testing. In contrast, during testing of unidirectional reinforced samples, all fibers are orientated in the longitudinal direction of the test bars, generating a higher bending strength at similar fiber volume contents than 2D woven fiber reinforcements.

Having a fiber content of only $45 \mathrm{vol} \%$ and without optimization of the process parameters, the alumina fiber reinforced composite has a bending strength $\sigma_{\mathrm{fm}}$ of almost 1,000 MPa. On the contrary, the low cost version with basalt fiber reinforcement shows a bending strength of $246 \mathrm{MPa}$, 
which is only slightly higher than the unreinforced material (and lower than modern, high-strength aluminum alloys). However, composite formation with basalt fibers leads to an increase in stiffness of the light metal. Furthermore, the theoretical increase in strength was not achieved by the present tests, because the quality of the basalt fibers was very inconsistent. The material data sheet from the manufacturer indicates an UTS of 3,000-4,800 MPa, and the oxidic basalt fiber should not show any reactions with the aluminum melt. Therefore, a dramatic increase in mechanical properties of basalt $\mathrm{F} / \mathrm{Al} 6 \mathrm{Si}$ MMC can be expected as soon as a higher quality of the fiber material is commercially available.

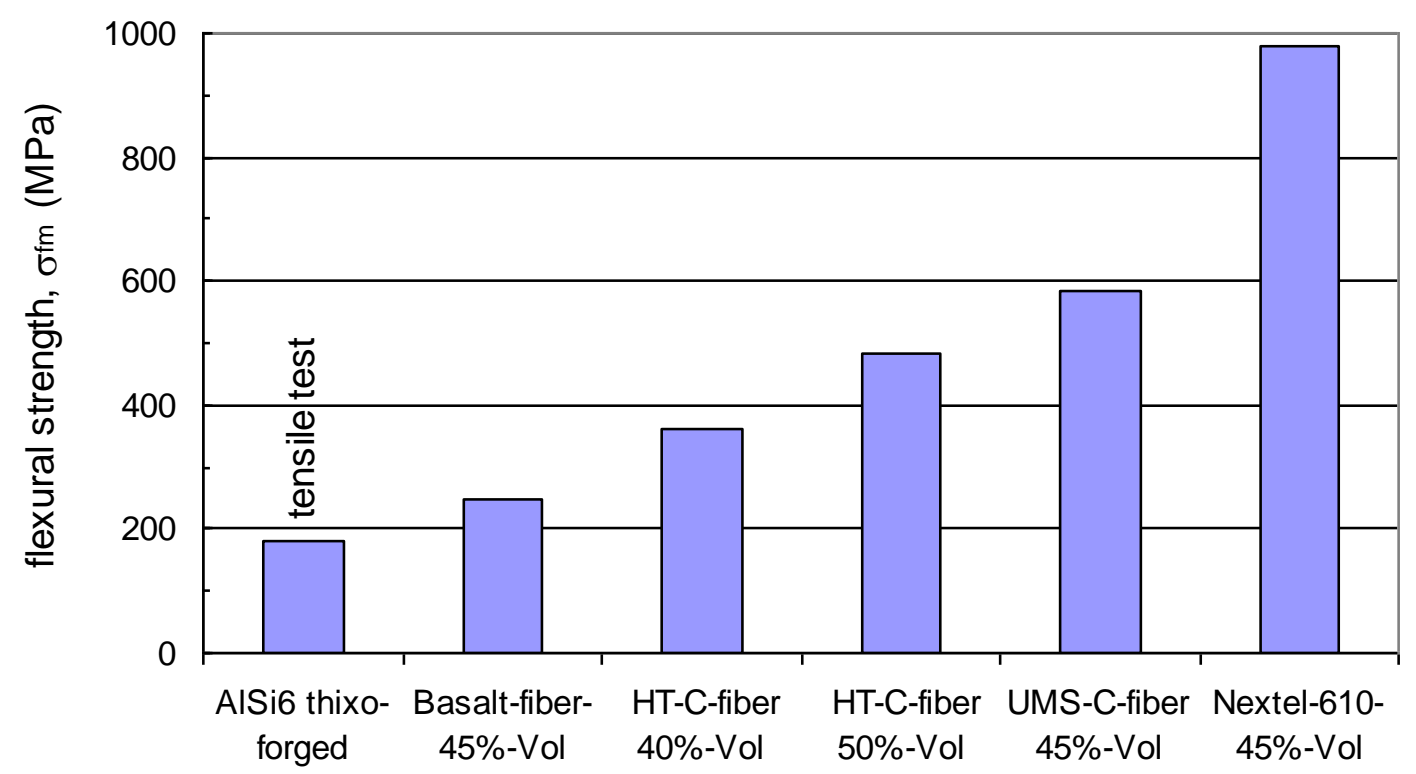

Fig. 24: Flexural strength, $\sigma_{\mathrm{fm}}$ (4-point-bending), of UD fiber reinforced $\mathrm{Al} 6 \mathrm{Si}$ (different fiber types)

In-between these extreme values, the two HT carbon fiber reinforced MMC yielded bending strength values of $363 \mathrm{MPa}$ and $485 \mathrm{MPa}$, depending on the fiber volume content (with the higher strength for a higher fiber content). A value of $\sigma_{\mathrm{fm}}=586 \mathrm{MPa}$ was obtained with UMS C-fiber reinforcement. Thereby, higher stiffness of the fibers leads to a better composite performance, even for lower fiber content, as described for the 2D reinforced MMC. Measurement of the composites' Young's modules by bending experiments did not yield reliable results, and the determination by means of ultrasonic waves was not possible for fiber-containing composites.

\section{Summary and Conclusions}

Fiber reinforced aluminum is a kind of material that has unique properties, like high specific strength and stiffness, if the characteristics of composites are considered during the manufacturing process, e. g. accurate fiber orientation, control of residual stresses, or the properties of the fiber/matrix interface. However, industrial cost targets can only be achieved by the application of carbon fibers, which have good mechanical properties but yet reasonable costs as compared to alumina or SiC fibers. Carbon fibers also lead to further reduction of the composites density, and thus increase of the specific material properties. But carbon fibers are sensitive to oxidation at high temperatures and chemical reaction if getting in contact with aluminum melts. Therefore, in order to avoid fiber damage during matrix infiltration, protective fiber coatings have to be applied in an additional process, or the process temperature and process time (duration of fiber/melt contact) have to be reduced. This approach would at the same time lead to a reduction of residual stresses and lower processing costs because of reduced cycle times and wear of the tools and equipment. 
Thixoforging of MMC in the semisolid state of the matrix alloy is an approach to a new processing route that considers lower process temperatures, reduced aluminum melt content, and lower cycle times. However, semisolid forging requires a globular microstructure of the metal, and due to the partially solid matrix alloy during infiltration, the flow paths need to be short. A suitable microstructure can be obtained by thermal spray deposition of metals, leading to fine, globular-like grains within the thermal spray splats. Additionally, the temperature of the substrate, which consists of the reinforcement fibers, can be controlled during thermal spraying, and the spray coated material is already impregnating into the topmost fiber layers. Twin-wire electric arc spraying, which is an industrially well-established technique, allows the deposition of a variety of aluminum alloys on reinforcement fibers with reduced thermal load on the substrate, high deposition rates and low costs.

Densification and forming in the semisolid state leads to a dense, well-infiltrated MMC component with a homogeneous, fine microstructure and reduces fiber damage by mechanical and chemical interaction due to short process times and low process temperatures. The fine-grained structure of thermally sprayed matrix alloy improves the impregnation behavior. Furthermore, the fiber content of the composite can be exactly matched by the coating thickness of the deposited coating. Therefore, coating processes and the required equipment have been developed in the present work for the manufacturing of coated fiber reinforcements (prepregs) that can be used as semifinished material for further processing by thixoforging. Thereby, the manufacturing of short fiber reinforced prepregs, UD continuous fiber reinforcements, 2D woven fiber structures, and semifinished material with tailored local reinforcement have been considered.

Al 6Si-MMC with different reinforcement fiber architecture and different fiber material (HT, IM, HM and UMS type carbon fibers, SiC fibers, Tyranno fibers, and alumina fibers type Nextel 610 and 720) were manufactured via thermal spraying of the matrix alloy under atmospheric conditions by a twin-wire electric arc process on the reinforcement fibers and subsequent densification of the prepregs by semisolid forging. Short fiber prepregs were manufactured by fixation of fiber fleece material in tentering frames and thermal spray coating. For continuous, unidirectional fiber reinforcement, a fiber winding device for well-defined fiber alignment, deposition and prestressing was developed. After coating application, the cylindrical prepregs are flattened due to residual stresses, forming rectangular prepreg sheets that can be trimmed and piled for further processing. For woven fiber cloth, a semi-industrial production line was developed which is suitable for continuous or incremental fiber coating, depending on the coating thickness necessary and the heat management during the coating process.

Mechanical properties of the MMC materials are generally lower than theoretically calculated values for strength and stiffness. This is mainly attributed to a weak interfacial bonding between fibers and matrix and low plasticity of the matrix. Best mechanical results have been obtained from alumina fiber reinforced samples. As a consequence, interfacial carbon fiber damage and matrix adhesion must be further improved by optimization of the process in order to make the beneficial properties of carbon fibers accessible for MMC by this process route and at low costs. An interesting alternative are basalt fibers, which are yet not available in sufficient quality. 


\section{Outlook}

Next Steps. The present work shows a variety of promising approaches and solutions for MMC processing. However, there are also a number of drawbacks that still prevent the realization of these alternative technologies in industrial applications. The aim of this work lies on the development of cost efficient technologies for the processing of light metal composites with improved properties, which implies further work that involves the following topics:

- Optimization of thermal spray parameters and torch design,

- Improvement of fiber-matrix adhesion,

- Influence of fiber coatings (thin films) on adhesion and MMC properties was not investigated in this work; this is considered in the next future.

- Improvement of the reheating process (IR-heating) with the aim on faster heating and better control of the semisolid temperature window,

- Better control of the matrix properties by thermal spray and reheating parameters,

- Variation of matrix alloy to achieve high-performance MMC components,

- Improvement of the fiber spreading unit (better matrix infiltration during coating, and thus further reduction of flow paths during thixoforging),

- Evaluation of mechanical properties (mainly Young's modulus and tensile properties; tribological properties for short fiber reinforcement),

- Adaptation of mechanical properties to special applications by fiber architecture design,

- Further work on tailored reinforcements.

Further Work - Tailored Fiber Reinforcement in Al-MMC. For local improvement of components mechanical properties, the manufacturing of a wheel rim with local reinforcement in the central area, see Fig. 25, is presented as a case study, for which a suitable processing technology for semifinished material was developed. Thereby, the aim was to produce semifinished parts with continuous fiber reinforcement around the hub, with the fibers being placed on their final intended position in the component. Therefore, the fibers should be well embedded in the matrix material, with the unreinforced material of the billet flowing around the reinforcement without disarranging it geometrically during thixoforging.

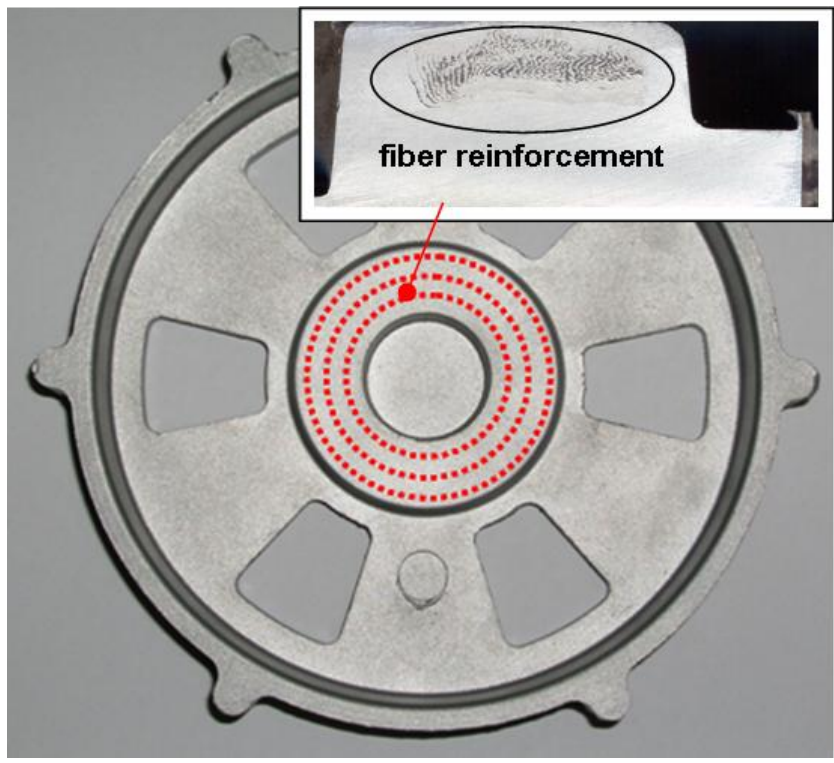

Fig. 25: Fiber reinforced rim manufactured by thixoforging; cross section of the centre with carbon fiber reinforcement 
HT type carbon fibers were used as reinforcement. The semifinished billet was from A356 alloy. The TS wire material was $\mathrm{Al} 6 \mathrm{Si}$ alloy. The locally reinforced, semifinished billet was heated by inductive heating prior to thixoforging in a hydraulic, axial press.

The process for manufacturing of prepreg material on a billet prior to thixoforging of the wheel rim is based on simultaneous winding and coating of continuous carbon fibers. Therefore, a step in the billet is used for application of the reinforcement, leading to a finally cylindrical semifinished part with pre-impregnated, continuous fiber reinforcement integrated in the billet. The unreinforced material of the billet delivers the metal material for complete mold filling of the rim die. The fiber reinforcement is applied and coated while winding a fiber strand on the cylinder, see Fig. 26. Thereby, taking into account suitable process parameters as developed during processing of UDfiber prepregs, there are three challenges to overcome:

- the fiber strand has to be spread exactly to the width of the desired reinforcement area (step in the billet), choosing an appropriate fiber strand thickness in order to obtain a thin, well impregnating fiber layer,

- the winding process has to be applied to the desired tension of the fibers in the matrix, thus being able to take influence on the final state of residual stress in the composite area, and

- the coating process itself requires adaptation of the coating area, coating distance and feed rate in order to obtain the pre-defined fiber volume content; this leads to the requirement of further adaptation of the cooling system to control deposition temperature.

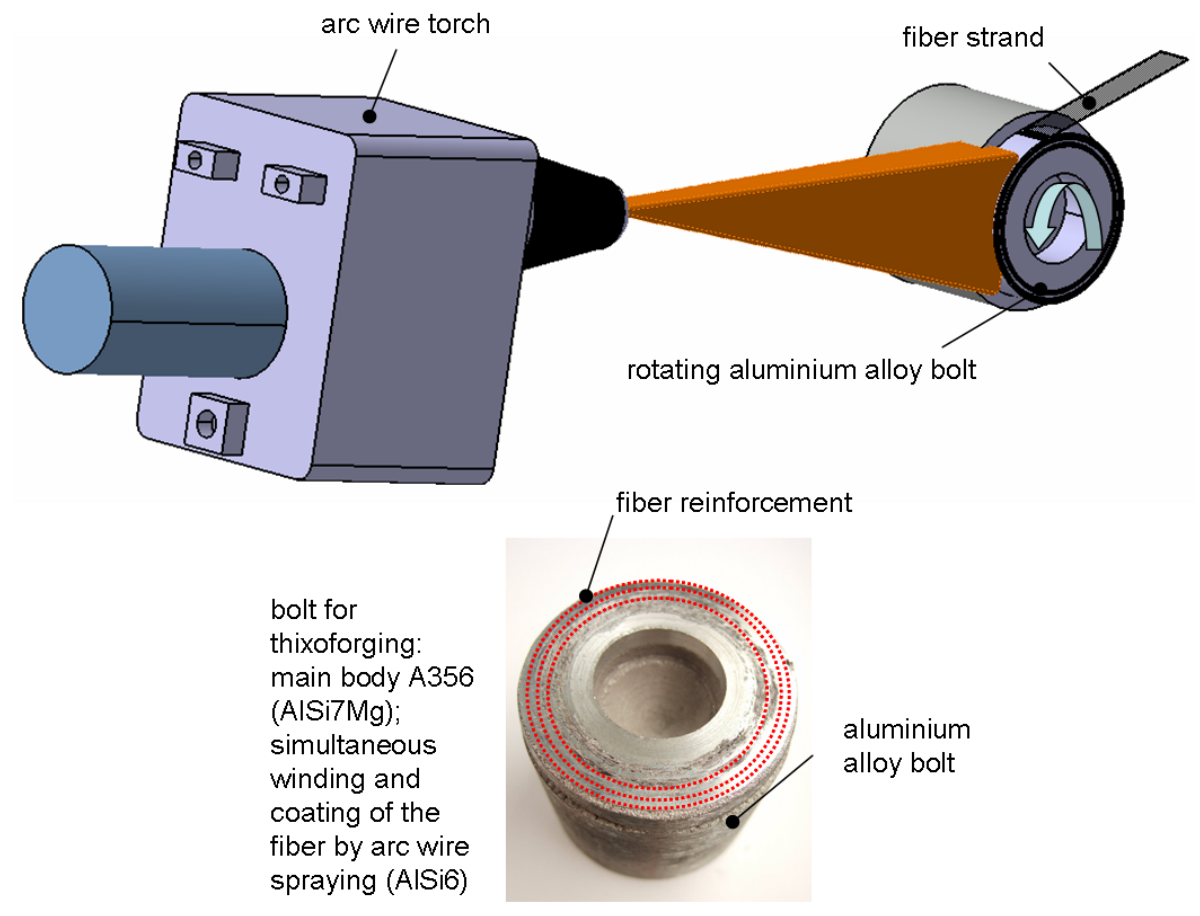

Fig. 26: Principle of simultaneous winding and coating; aluminum alloy semifinished part (billet) with coated carbon fiber reinforcement (additional, dotted lines showing position of the fibers)

After processing of the semifinished parts, the cylinders were heated up by an inductive heating device and finally thixoforged to the near net shape component (wheel rim). During the thixoforging process, the fiber reinforcement was disarranged to a certain extent, see Fig. 25, detail. However, work on this subject is still in progress and requires further research and optimization with the aim on better control of form filling and flow paths during the densification process. 


\section{Acknowledgements}

The authors thank the Ministry of Science, Research and Art of the State of Baden-Württemberg and the Stiftung Industrieforschung e. V., Cologne, for financial support of this work. Furthermore, the authors thank the Institute for Metal Forming Technology, Universität Stuttgart, for thixoforging experiments as well as description and images of the thixoforging process and equipment. The authors also thank Dr.-Ing. Konstantin von Niessen, formerly IFKB, Universität Stuttgart, for his large contributions in terms of research ideas, results and images, and Dr. Florian Kauffmann, formerly Max Plank Institute for Metals Research Stuttgart, for SEM, FIB and TEM investigations.

\section{References}

[1] M.F. Ashby: Materials Selection in Mechanical Design ( ${ }^{\text {rd }}$ ed., Butterworth-Heinemann, Burlington, 2005)

[2] T.W. Clyne, P.J. Withers: An Introduction to Metal Matrix Composites (Cambridge Solid State Science Series, E.A. Davis, I.M. Ward (eds.), Cambridge University Press, 1993)

[3] T.J. Whalen and A.T Anderson: J. Amer. Ceram. Soc. Vol. 58 (1975), p. 396-398

[4] L.J. Ebert and O.K Wright, in: Interfaces in Metal Matrix Composites, edited by A.G. Metcalfe, Academic Press, New York (1974), p. 31

[5] R. Gadow and M. Speicher: Ceram. Trans. Vol. 103 (2000), p. 277-291

[6] R. Gadow: Die Silizierung von Kohlenstoff (Dissertation, Universität Karlsruhe, 1986)

[7] R.E. Tressler, in: Interfaces in Metal Matrix Composites, edited by A.G. Metcalfe, Academic Press, New York (1974), p. 285

[8] G. Ibe, in: Metallische Verbundwerkstoffe, edited by K.U. Kainer, DGM Informationsgesellschaft, Oberursel (1994), p. 3-41

[9] H.P. Degischer, in: Metallische Verbundwerkstoffe, edited by K.U. Kainer, DGM Informationsgesellschaft, Oberursel (1994), p. 139-168

[10] R. Gadow, M. Speicher, K. v. Niessen, P. Unseld, G. Messmer and K. Siegert, European Patent EP 1685263 B1 (2008)

[11] D. Gay and S.V. Hoa: Composite materials : design and applications $\left(2^{\text {nd }}\right.$ ed., CRC Press, Boca Raton, 2007)

[12] D.H. Kirkwood: Int. Mater. Rev. Vol. 39, No. 5 (1994), p.173-189

[13] R. Gadow, K. v. Niessen and P. Unseld, in: Proc. Int. Conf. Advanced Metallic Materials, November 5-7, 2003, Smolenice, Slovakia, edited by J. Jerz, P. Sebo, M. Zemankova (Institute of Materials and Machine Mechanics, Slovak Academy of Sciences, Bratislava, 2003), p. 101-105. - ISBN 80-969011-7-6

[14] R. Gadow, K. v. Niessen and M. Wenzelburger: Adv. Sci. Technol. Vol. 50 (2006), p. 57-63

[15] P. Uggowitzer, G.-C. Gullo and A. Wahlen, in: Proc. Int. Conf. 'Vom Werkstoff zum Bauteil', edited by H. Kaufmann, P. Uggowitzer (LKR-Verlag, Randshofen, 2000), p. 95-107

[16] A. Leatham, A. Ogilvy, P. Chesney, J.V. Wood: Met. Mater. Vol. 5, No. 3 (1989), p. 140-143

[17] L. Pawlowski: The science and engineering of thermal spray coatings (John Wiley, Chichester, 1995) 
[18] E. Kretzschmar: Metall-, Keramik- und Plasmaspritzen (VEB Verlag Technik, Berlin, 1969)

[19] K. v. Niessen: Thermisches Spritzen als innovatives Verfahren der Textilbeschichtung (Shaker, Aachen, 2007; and: Dissertation, Universität Stuttgart, 2007)

[20] R. Gadow and K. v. Niessen: Ceram. Eng. Sci. Proc. Vol. 26, No. 3 (2005), p. 299-307

[21] H.-D. Steffens, H. Kern, J. Janczak and R. Kaczmarek, in: Verbundwerkstoffe und Werkstoffverbunde, Proc. of the Int. Symp. Verbundwerkstoffe und Werkstoffverbunde, Chemnitz, June 19-19, 1992, edited by G. Leonhardt, G. Ondracek (DGM Informationsgesellschaft, Oberursel, 1993)

[22] H.-D. Steffens, J. Wilden, K. Nassenstein and U. Erning, in: Verbundwerkstoffe und Werkstoffverbunde, Proc. of the Conf. Verbundwerkstoffe und Werkstoffverbunde, Bayreuth, Oct. 24/25, 1995, edited by G. Ziegler (DGM Informationsgesellschaft, Oberursel, 1996)

[23] K. Hoffmann, T. Süß, G. Pursche, G. Leonhardt, K. Fleischer, H.-D. Steffens, Z. Babiak and W. Brandl, in: Verbundwerkstoffe und Werkstoffverbunde, Proc. of the Int. Symp. Verbundwerkstoffe und Werkstoffverbunde, Chemnitz, June 19-19, 1992, edited by G. Leonhardt, G. Ondracek (DGM Informationsgesellschaft, Oberursel, 1993)

[24] R. Gadow and K. v. Niessen: Ceram. Trans. Vol. 151 (2003), p. 3-18

[25] K. Siegert, R. Gadow, K. v. Niessen, P. Unseld and M. Speicher, in: Proc. $8^{\text {th }}$ Int. Conf. Semisolid Processing of Alloys and Composites (S2P 2004), September 21-23, 2004, Limassol, Cyprus (Pub. NADCA Wheeling, Illinois, USA, 2004), Paper \# 23-3

[26] C.A. Volkert, B. Heiland and F. Kauffmann: Prakt. Metall. Vol. 40 (2003), p. 193-208

[27] F. Altmann: Prakt. Metall. Vol. 40 (2003), p. 175-183

[28] K.U. Kainer (ed.): Metal Matrix Composites - Custom-made Materials for Automotive and Aerospace Engineering (Wiley-VCH, Weinheim, 2006)

[29] Industrial standard EN 658-3:2002, Advanced technical ceramics - Mechanical properties of ceramic composites at room temperature - Part 3: Determination of flexural strength, German version DIN EN 658-3:2002-11 (Beuth Verlag, Berlin, 2002) 